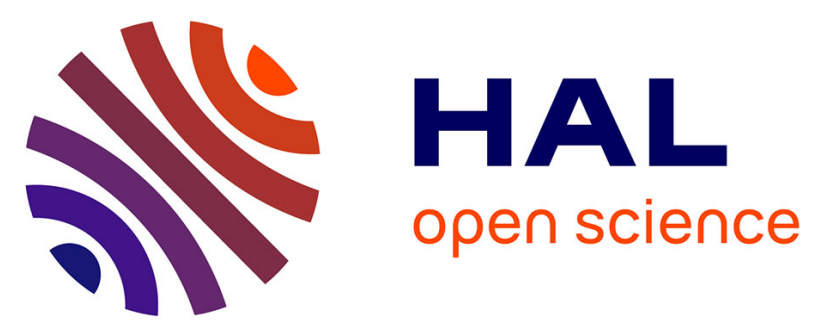

\title{
Structure-Directing Effects of Coordinating Solvents, Ammonium and Phosphonium Counterions in Uranyl Ion Complexes with 1,2-, 1,3-, and 1,4-Phenylenediacetates
}

Pierre Thuéry, Youssef Atoini, Jack Harrowfield

\section{To cite this version:}

Pierre Thuéry, Youssef Atoini, Jack Harrowfield. Structure-Directing Effects of Coordinating Solvents, Ammonium and Phosphonium Counterions in Uranyl Ion Complexes with 1,2-, 1,3-, and 1,4Phenylenediacetates. Inorganic Chemistry, 2020, 59, pp.2503-2518. 10.1021/acs.inorgchem.9b03404 . cea-02458785

\section{HAL Id: cea-02458785 \\ https://hal-cea.archives-ouvertes.fr/cea-02458785}

Submitted on 4 Feb 2020

HAL is a multi-disciplinary open access archive for the deposit and dissemination of scientific research documents, whether they are published or not. The documents may come from teaching and research institutions in France or abroad, or from public or private research centers.
L'archive ouverte pluridisciplinaire HAL, est destinée au dépôt et à la diffusion de documents scientifiques de niveau recherche, publiés ou non, émanant des établissements d'enseignement et de recherche français ou étrangers, des laboratoires publics ou privés. 


\title{
Structure-Directing Effects of Coordinating Solvents, Ammonium and Phosphonium Counterions in Uranyl Ion Complexes with
}

\section{1,2-, 1,3- and 1,4-Phenylenediacetates}

\author{
Pierre Thuéry, ${ }^{*}, \dagger$ Youssef Atoini ${ }^{\ddagger}$ and Jack Harrowfield $*, \dot{\dagger}$ \\ †NIMBE, CEA, CNRS, Université Paris-Saclay, CEA Saclay, 91191 Gif-sur-Yvette, France \\ †ISIS, Université de Strasbourg, 8 allée Gaspard Monge, 67083 Strasbourg, France
}

\begin{abstract}
The three isomers 1,2-, 1,3- and 1,4-phenylenediacetic acids (1,2-, 1,3- and 1,4-pdaH $\mathrm{pl}_{2}$ have been used to synthesize 16 uranyl ion complexes under solvo-hydrothermal conditions and in the presence of various coligands and organic counterions. The two neutral and homoleptic complexes $\left[\mathrm{UO}_{2}(1,2-p d a)\right] \cdot \mathrm{CH}_{3} \mathrm{CN}(\mathbf{1})$ and $\left[\mathrm{UO}_{2}(1,3-\mathrm{pda})\right]$ (2) crystallize as diperiodic assemblies with slightly different coordination modes of the ligands, but the same sql topology. Introduction of the coordinating solvents $N$-methyl-2-pyrrolidone (NMP) or $N, N^{\prime}$ dimethylpropyleneurea (DMPU) in the uranyl coordination sphere produces the four complexes $\left[\mathrm{UO}_{2}(1,2-\right.$ pda)(DMPU)] (3), [UO 2 (1,3-pda)(NMP)] (4), [UO 2 (1,4-pda)(NMP)] (5), and [UO 2 (1,4-pda)(DMPU)] (6), which are either monoperiodic (4) or diperiodic species with the fes (3 and 5) or 3,4L13 (6) topology. The presence of dimethylammonium cations is associated with the formation of ladder-like monoperiodic polymers with the 1,2 isomer in the complexes $\left[\mathrm{H}_{2} \mathrm{NMe}_{2}\right]_{2}\left[\left(\mathrm{UO}_{2}\right)_{2}(1,2-\text {-pda })_{3}\right] \cdot \mathrm{H}_{2} \mathrm{O}(7)$ and $\left[\mathrm{H}_{2} \mathrm{NMe}_{2}\right]_{2}\left[\left(\mathrm{UO}_{2}\right)_{2}(1,2-\text { pda })_{3}\right] \cdot 3 \mathrm{H}_{2} \mathrm{O}(8)$, while a conformational change giving the 1,3 and 1,4 isomers a pincer-like geometry favors the formation of dinuclear ring subunits assembled into daisychain-like monoperiodic polymers in $\left[\mathrm{H}_{2} \mathrm{NMe}_{2}\right]_{2}\left[\left(\mathrm{UO}_{2}\right)_{2}(1,3-\mathrm{pda})_{3}\right] \cdot 0.5 \mathrm{H}_{2} \mathrm{O}(9)$, $\left[\mathrm{H}_{2} \mathrm{NMe}_{2}\right]_{2}\left[\left(\mathrm{UO}_{2}\right)_{2}(1,4-\mathrm{pda})_{3}\right](\mathbf{1 0})$, and the mixed-ligand species $\left[\mathrm{H}_{2} \mathrm{NMe}_{2}\right]_{2}\left[\left(\mathrm{UO}_{2}\right)_{2}(1,2-\right.$ pda $\left.)(1,4-\text { pda })_{2}\right](\mathbf{1 1})$. The unique complex including guanidinium cations, $\left[\mathrm{C}\left(\mathrm{NH}_{2}\right)_{3}\right]_{2}\left[\left(\mathrm{UO}_{2}\right)_{2}(1,2-\text { pda })_{3}\right] \cdot 0.5 \mathrm{H}_{2} \mathrm{O} \cdot \mathrm{CH}_{3} \mathrm{CN}(\mathbf{1 2})$, crystallizes as a diperiodic polymer with the hcb topology. Due to differences in ligand conformations, the phosphoniumcontaining complexes $\left[\mathrm{PPh}_{3} \mathrm{Me}\right]_{2}\left[\left(\mathrm{UO}_{2}\right)_{2}(1,3-\mathrm{pda})_{3}\right](\mathbf{1 3})$ and $\left[\mathrm{PPh}_{4}\right]_{2}\left[\left(\mathrm{UO}_{2}\right)_{2}(1,4-p d a)_{3}\right]$ (14) contain ladder-like and daisychain-like monoperiodic polymers, respectively, while only the latter geometry is found in the mixedcation complexes $\left[\mathrm{PPh}_{3} \mathrm{Me}\right]\left[\mathrm{H}_{2} \mathrm{NMe}_{2}\right]\left[\left(\mathrm{UO}_{2}\right)_{2}(1,4-\text { pda })_{3}\right] \cdot \mathrm{H}_{2} \mathrm{O}(\mathbf{1 5})$ and $\left[\mathrm{PPh}_{3} \mathrm{Me}\right]\left[\mathrm{H}_{2} \mathrm{NMe}_{2}\right]\left[\left(\mathrm{UO}_{2}\right)_{2}(1,2-\right.$ pda $)(1,4-$ pda $)_{2}$ ( (16). The influence of ligand conformation and the structure-directing effects of coligands and counterions throughout the series are discussed. The uranyl emission spectra of 14 of the complexes display the usual vibronic fine structure, the peak positions being dependent on the number of equatorial donors.
\end{abstract}




\section{INTRODUCTION}

Although they are attractive and readily available ligands, the three isomeric 1,2-, 1,3- and 1,4phenylenediacetates $\left(1,2-, 1,3-\right.$ and 1,4- $\left.\mathrm{pda}^{2-}\right)$ are newcomers in the field of uranyl-organic coordination polymer ${ }^{1-5}$ and porous frameworks ${ }^{6-8}$ studies, in which polycarboxylates are staple assemblers, and they have been the subject of only two reports up to now. ${ }^{9,10}$ These anions unite a rigid phenylenic platform and two flexible arms, thus displaying a greater geometric variety than the phenylenedicarboxylate analogues, while, as with the latter, the existence of three isomeric forms allows for an assessment of the effect of the variable separation between the coordinating groups on the periodicity and topology of the assemblies formed. We have previously reported mono- or diperiodic (denoted 1D or 2D for convenience) coordination polymers based on these ligands, the 1D chains having in some cases a tubelike shape, which incorporate diverse organic or metal-containing counterions, particularly those of the form $\left[\mathrm{M}(\mathrm{L})_{n}\right]^{q+}$, in which $\mathrm{M}=$ transition metal cation, $\mathrm{L}=2,2^{\prime}$-bipyridine (bipy) or 1,10 phenanthroline (phen), $n=2$ or 3 , and $q=1$ or 2 , and $\mathrm{Ni}^{\mathrm{II}}$ or $\mathrm{Cu}^{\mathrm{II}}$ complexes with azamacrocycles, as well as $\mathrm{Pb}^{\mathrm{II}}$ cations. ${ }^{9,10}$ Overall, all three ligands have a strong tendency to favour the formation of $1 \mathrm{D}$ polymers, no higher periodicity having been obtained with 1,2-pda ${ }^{2-}$ alone (not associated with 1,4-pda ${ }^{2-}$ ) in particular. Both 1,3- and 1,4-pda ${ }^{2-}$ were shown to give some examples of 2D networks with separate $\left[\mathrm{M}(\mathrm{L})_{n}\right]^{q+}$ counterions, in which case they display topologies of the hcb type or derived from it, with 2-fold interpenetration in one case. Another example of a $2 \mathrm{D}$ assembly involves $1,3-\mathrm{pda}^{2-}$ and $[\mathrm{Ni}(\text { cyclam })]^{2+}$ counterions $($ cyclam $=$ 1,4,8,11-tetraazacyclotetradecane), the $\mathrm{Ni}^{\mathrm{II}}$ cations linking triple-stranded ribbons and being thus part of the polymeric assembly. Heterometallic 2D networks including additional $\mathrm{Pb}^{\mathrm{II}}$ cations were also found with both 1,3- and 1,4-pda ${ }^{2-}$. In order to examine further the effect of counterions on the nature of the polymers formed with these three ligands, we have now synthesized 16 complexes which are either neutral, some of them involving coordinated solvent 
molecules ( $N$-methyl-2-pyrrolidone or $N, N^{\prime}$-dimethylpropyleneurea), or anionic, the latter being associated with dimethylammonium, guanidinium, or phosphonium $\left(\mathrm{PPh}_{3} \mathrm{Me}^{+}, \mathrm{PPh}_{4}^{+}\right)$ counterions, or mixtures thereof. These complexes, which have been characterized by their crystal structure and, in all but two cases, by their emission spectrum in the solid state, are most often 1D species, but here also examples of 2D polymerization are found, in particular the first such species involving the 1,2 isomer alone.

\section{EXPERIMENTAL SECTION}

Syntheses. Caution! Uranium is a radioactive and chemically toxic element, and uranium-containing samples must be handled with suitable care and protection.

$\mathrm{UO}_{2}\left(\mathrm{NO}_{3}\right)_{2} \cdot 6 \mathrm{H}_{2} \mathrm{O}$ (depleted uranium, R. P. Normapur, 99\%) was purchased from Prolabo, and 1,2-, 1,3- and 1,4-phenylenediacetic acids were from Aldrich. Elemental analyses were performed by MEDAC Ltd. at Chobham, UK. For all syntheses, the mixtures of $\mathrm{UO}_{2}\left(\mathrm{NO}_{3}\right)_{2} \cdot 6 \mathrm{H}_{2} \mathrm{O}(50 \mathrm{mg}, 0.10 \mathrm{mmol}$ for 3-7 and 10; $35 \mathrm{mg}, 0.07 \mathrm{mmol}$ for all other compounds), dicarboxylic acid (20 mg, $0.10 \mathrm{mmol}$ in the general case; $10 \mathrm{mg}, 0.05 \mathrm{mmol}$ of each of the two acids for $\mathbf{1 1}$ and $\mathbf{1 6})$, and additional reactants $(0.10 \mathrm{mmol})$ in demineralized water $(0.7 \mathrm{~mL})$ and organic solvent $(0.2 \mathrm{~mL})$ were placed in $10 \mathrm{~mL}$ tightly closed glass vessels and heated at $140^{\circ} \mathrm{C}$ under autogenous pressure. The crystals were grown in the hot, pressurized solutions. A summary of the synthesis conditions (cosolvent, additional reactants, heating duration and yield based on $U$ ), and elemental analytical results is given in Table 1 . 
Table 1. Summary of the Synthesis Conditions and Elemental Analysis Results

\begin{tabular}{|c|c|c|c|c|c|c|c|c|c|c|}
\hline \multirow{2}{*}{ Compound } & \multirow{2}{*}{$\begin{array}{c}\text { Organic } \\
\text { Cosolvent }\end{array}$} & \multirow{2}{*}{$\begin{array}{l}\text { Additional } \\
\text { Reactant }^{a} \\
\end{array}$} & \multirow{2}{*}{ Duration } & \multirow{2}{*}{$\begin{array}{c}\begin{array}{c}\text { Yield } \\
(\%)\end{array} \\
\end{array}$} & \multicolumn{3}{|c|}{ Anal. calcd (\%) } & \multicolumn{3}{|c|}{ Anal. found (\%) } \\
\hline & & & & & $\mathrm{C}$ & $\mathrm{H}$ & $\mathrm{N}$ & $\mathrm{C}$ & $\mathrm{H}$ & $\mathrm{N}$ \\
\hline$\left[\mathrm{UO}_{2}(1,2-\mathrm{pda})\right] \cdot \mathrm{CH}_{3} \mathrm{CN}(\mathbf{1})$ & $\mathrm{CH}_{3} \mathrm{CN}$ & $\left\{\mathrm{Co}(\mathrm{en})_{3} \mathrm{Cl}_{3}\right\}$ & 6 weeks & 40 & 28.64 & 2.20 & 2.78 & 28.49 & 2.26 & 2.89 \\
\hline$\left[\mathrm{UO}_{2}(1,3-\mathrm{pda})\right](\mathbf{2})$ & $\mathrm{CH}_{3} \mathrm{CN}$ & $\left\{\mathrm{enH}_{2}(\mathrm{OTf})_{2}\right\}$ & 1 week & 62 & 25.99 & 1.74 & & 26.84 & 1.95 & \\
\hline$\left[\mathrm{UO}_{2}(1,2-\mathrm{pda})(\mathrm{DMPU})\right](\mathbf{3})$ & DMPU & & 1 week & 41 & 32.55 & 3.41 & 4.75 & 32.26 & 3.47 & 4.79 \\
\hline$\left[\mathrm{UO}_{2}(1,3-\mathrm{pda})(\mathrm{NMP})\right](\mathbf{4})$ & NMP & & 3 days & 73 & 32.10 & 3.05 & 2.50 & 31.90 & 3.07 & 2.80 \\
\hline$\left[\mathrm{UO}_{2}(1,4-\mathrm{pda})(\mathrm{NMP})\right](\mathbf{5})$ & NMP & & 3 days & 59 & 32.10 & 3.05 & 2.50 & 32.20 & 3.01 & 2.60 \\
\hline$\left[\mathrm{UO}_{2}(1,4-\mathrm{pda})(\mathrm{DMPU})\right](\mathbf{6})$ & DMPU & & 1 week & low & & & & & & \\
\hline$\left[\mathrm{H}_{2} \mathrm{NMe}_{2}\right]_{2}\left[\left(\mathrm{UO}_{2}\right)_{2}(1,2-\mathrm{pda})_{3}\right] \cdot \mathrm{H}_{2} \mathrm{O}(7)$ & DMF & & 1 week & 37 & 33.29 & 3.45 & 2.28 & 33.12 & 3.41 & 2.41 \\
\hline$\left[\mathrm{H}_{2} \mathrm{NMe}_{2}\right]_{2}\left[\left(\mathrm{UO}_{2}\right)_{2}(1,2-\text { pda })_{3}\right] \cdot 3 \mathrm{H}_{2} \mathrm{O}(\mathbf{8})$ & DMF & $\left\{\mathrm{Ni}\left(\mathrm{NO}_{3}\right)_{2}\right\}$ & 3 days & 34 & 32.34 & 3.67 & 2.22 & 32.86 & 3.26 & 2.29 \\
\hline$\left[\mathrm{H}_{2} \mathrm{NMe}_{2}\right]_{2}\left[\left(\mathrm{UO}_{2}\right)_{2}(1,3-\mathrm{pda})_{3}\right] \cdot 0.5 \mathrm{H}_{2} \mathrm{O}(\mathbf{9})$ & DMF & $\left\{\mathrm{C}\left(\mathrm{NH}_{2}\right)_{3} \mathrm{NO}_{3}\right\}$ & 3 days & low & & & & & & \\
\hline$\left[\mathrm{H}_{2} \mathrm{NMe}_{2}\right]_{2}\left[\left(\mathrm{UO}_{2}\right)_{2}(1,4-\mathrm{pda})_{3}\right](\mathbf{1 0})$ & DMF & & 1 week & 40 & 33.79 & 3.34 & 2.32 & 33.29 & 3.31 & 2.63 \\
\hline$\left[\mathrm{H}_{2} \mathrm{NMe}_{2}\right]_{2}\left[\left(\mathrm{UO}_{2}\right)_{2}(1,2-\right.$ pda $\left.)(1,4 \text {-pda })_{2}\right]$ (11) & DMF & & 3 days & 26 & 33.79 & 3.34 & 2.32 & 33.72 & 3.35 & 2.42 \\
\hline$\left[\mathrm{C}\left(\mathrm{NH}_{2}\right)_{3}\right]_{2}\left[\left(\mathrm{UO}_{2}\right)_{2}(1,2-\mathrm{pda})_{3}\right] \cdot 0.5 \mathrm{H}_{2} \mathrm{O} \cdot \mathrm{CH}_{3} \mathrm{CN}(\mathbf{1 2})$ & $\mathrm{CH}_{3} \mathrm{CN}$ & $\mathrm{C}\left(\mathrm{NH}_{2}\right)_{3} \mathrm{NO}_{3}$ & 3 weeks & 16 & 31.74 & 3.13 & 7.62 & 31.44 & 2.96 & 7.44 \\
\hline$\left[\mathrm{PPh}_{3} \mathrm{Me}\right]_{2}\left[\left(\mathrm{UO}_{2}\right)_{2}(1,3-\mathrm{pda})_{3}\right](\mathbf{1 3})$ & DMF & $\mathrm{PPh}_{3} \mathrm{MeBr}$ & 1 day & 43 & 47.84 & $3.78^{b}$ & & 47.88 & 3.96 & \\
\hline$\left[\mathrm{PPh}_{4}\right]_{2}\left[\left(\mathrm{UO}_{2}\right)_{2}(1,4-\mathrm{pda})_{3}\right](\mathbf{1 4})$ & DMF & $\mathrm{PPh}_{4} \mathrm{Br}$ & 1 week & 48 & 52.18 & 3.59 & & 51.79 & 3.38 & \\
\hline$\left[\mathrm{PPh}_{3} \mathrm{Me}\right]\left[\mathrm{H}_{2} \mathrm{NMe}_{2}\right]\left[\left(\mathrm{UO}_{2}\right)_{2}(1,4-\mathrm{pda})_{3}\right] \cdot \mathrm{H}_{2} \mathrm{O}(\mathbf{1 5})$ & DMF & $\mathrm{PPh}_{3} \mathrm{MeBr}$ & 3 days & 74 & 42.01 & 3.59 & 0.96 & 41.35 & 3.33 & 1.13 \\
\hline$\left[\mathrm{PPh}_{3} \mathrm{Me}\right]\left[\mathrm{H}_{2} \mathrm{NMe}_{2}\right]\left[\left(\mathrm{UO}_{2}\right)_{2}(1,2-\mathrm{pda})(1,4-\mathrm{pda})_{2}\right](\mathbf{1 6})$ & DMF & $\mathrm{PPh}_{3} \mathrm{MeBr}$ & 1 week & 10 & 42.54 & 3.50 & 0.97 & 42.44 & 3.70 & 0.95 \\
\hline
\end{tabular}

$\overline{{ }^{a}}$ Additional reactants in curly brackets are absent from the final compounds; en = ethylenediamine, OTf $=$ trifluoromethanesulfonate. ${ }^{b}$ Analytical results for $\mathbf{1 3}$ include two extra water molecules.

Crystallography. The data were collected at 100(2) K on a Nonius Kappa-CCD area detector diffractometer ${ }^{11}$ using graphite-monochromated $\operatorname{Mo~K\alpha }$ radiation $(\lambda=0.71073 \AA)$. The crystals were introduced into glass capillaries with a protective coating of Paratone- $\mathrm{N}$ oil (Hampton Research). The unit cell parameters were determined from ten frames, then refined on all data. The data (combinations of $\varphi$ - and $\omega$-scans with a minimum redundancy of 4 for $90 \%$ of the reflections) were processed with HKL2000. ${ }^{12}$ Absorption effects were corrected empirically with the program SCALEPACK. ${ }^{12}$ The structures were solved by intrinsic phasing with SHELXT, ${ }^{13}$ expanded by subsequent difference Fourier synthesis and refined by fullmatrix least-squares on $F^{2}$ with SHELXL-2014. ${ }^{14}$ All non-hydrogen atoms were refined with anisotropic displacement parameters. The hydrogen atoms bound to oxygen and nitrogen atoms were retrieved from difference Fourier maps when possible, or in some cases introduced at calculated positions, as were the carbon-bound hydrogen atoms; all were treated as riding atoms with an isotropic displacement parameter equal to 1.2 times that of the parent atom (1.5 for 
$\mathrm{CH}_{3}$, with optimized geometry). In complex $\mathbf{1 0}$, the nitrogen atom of one dimethylammonium counterion is disordered over two positions which were refined with occupancy parameters constrained to sum to unity, and the other two dimethylammonium cations are disordered around inversion centers. In complex 13, the aromatic ring of one of the dicarboxylate ligands is disordered over two positions related by inversion. The Flack parameter values of $0.258(12)$ for $\mathbf{8}, 0.494(8)$ for $\mathbf{1 1}$, and $0.508(11)$ for 12 are indicative of inversion twinning. 2-Component twinning in 16 was detected with TwinRotMat $\left(\right.$ PLATON $\left.^{15}\right)$ and was taken into account. Crystal data and structure refinement parameters are given in Table 2. The molecular plots (all with displacement ellipsoids drawn at the $50 \%$ probability level) were drawn with ORTEP-3, ${ }^{16}$ and the polyhedral representations with VESTA (Version 3.4.4). ${ }^{17}$ The topological analyses were conducted with ToposPro. ${ }^{18}$

Luminescence Measurements. Emission spectra were recorded on solid samples using a Horiba-Jobin-Yvon IBH FL-322 Fluorolog 3 spectrometer equipped with a $450 \mathrm{~W}$ xenon arc lamp, double-grating excitation and emission monochromators $(2.1 \mathrm{~nm} / \mathrm{mm}$ of dispersion; 1200 grooves $/ \mathrm{mm}$ ) and a TBX-04 single photon-counting detector. The powdered compounds were pressed to the wall of a quartz tube, and the measurements were performed using the right angle mode. An excitation wavelength of $420 \mathrm{~nm}$, a commonly used point although only part of a broad manifold, was used in all cases and the emission was monitored between 450 and 650 nm. The quantum yield measurements were performed by using a Hamamatsu Quantaurus C11347 absolute photoluminescence quantum yield spectrometer and exciting the sample between 300 and $400 \mathrm{~nm}$. 
Table 2. Crystal data and structure refinement details

\begin{tabular}{|c|c|c|c|c|c|c|c|c|}
\hline & 1 & 2 & 3 & 4 & 5 & 6 & 7 & 8 \\
\hline chemical formula & $\mathrm{C}_{12} \mathrm{H}_{11} \mathrm{NO}_{6} \mathrm{U}$ & $\mathrm{C}_{10} \mathrm{H}_{8} \mathrm{O}_{6} \mathrm{U}$ & $\mathrm{C}_{16} \mathrm{H}_{20} \mathrm{~N}_{2} \mathrm{O}_{7} \mathrm{U}$ & $\mathrm{C}_{15} \mathrm{H}_{17} \mathrm{NO}_{7} \mathrm{U}$ & $\mathrm{C}_{15} \mathrm{H}_{17} \mathrm{NO}_{7} \mathrm{U}$ & $\mathrm{C}_{16} \mathrm{H}_{20} \mathrm{~N}_{2} \mathrm{O}_{7} \mathrm{U}$ & $\mathrm{C}_{34} \mathrm{H}_{42} \mathrm{~N}_{2} \mathrm{O}_{17} \mathrm{U}_{2}$ & $\mathrm{C}_{34} \mathrm{H}_{46} \mathrm{~N}_{2} \mathrm{O}_{19} \mathrm{U}_{2}$ \\
\hline$M\left(\mathrm{~g} \mathrm{~mol}^{-1}\right)$ & 503.25 & 462.19 & 590.37 & 561.32 & 561.32 & 590.37 & 1226.75 & 1262.79 \\
\hline cryst syst & Triclinic & Triclinic & Monoclinic & Triclinic & Monoclinic & Triclinic & Triclinic & Orthorhombic \\
\hline space group & $P_{1}$ & $P_{\overline{1}}$ & $P 2{ }_{1} / n$ & $P_{\overline{1}}$ & $P 2_{1} / c$ & $P_{\overline{1}}$ & $P \overline{1}$ & $P 212121$ \\
\hline$a(\AA))$ & $8.4521(5)$ & $5.6840(4)$ & $10.5231(3)$ & $7.6672(5)$ & $7.5010(2)$ & $8.4130(8)$ & $7.6382(3)$ & $7.7336(3)$ \\
\hline$b(\AA$ & $9.1635(8)$ & $9.1367(4)$ & $9.5515(4)$ & $9.5944(10)$ & $12.9471(6)$ & $10.7724(9)$ & $13.6662(7)$ & $17.1240(11)$ \\
\hline$c(\AA)$ & $9.1700(7)$ & $11.1165(7)$ & $17.4377(7)$ & $11.7905(13)$ & $17.0981(9)$ & $11.0839(11)$ & $19.0828(10)$ & $30.9092(18)$ \\
\hline$\alpha\left({ }^{\circ}\right)$ & $76.728(4)$ & $71.588(4)$ & 90 & $71.491(5)$ & 90 & 109.411(5) & 97.104(3) & 90 \\
\hline$\beta\left(^{\circ}\right)$ & $80.633(5)$ & $86.119(3)$ & $98.628(2)$ & $80.260(6)$ & 96.999(3) & $106.854(5)$ & $90.847(3)$ & 90 \\
\hline$\gamma\left({ }^{\circ}\right)$ & $83.637(5)$ & $87.957(4)$ & 90 & $82.217(6)$ & 90 & $97.085(5)$ & $102.018(3)$ & 90 \\
\hline$V\left(\AA^{3}\right)$ & $680.04(9)$ & $546.44(6)$ & $1732.85(11)$ & $807.51(14)$ & $1648.13(12)$ & $879.45(15)$ & 1931.66(16) & 4093.3(4) \\
\hline$Z$ & 2 & 2 & 4 & 2 & 4 & 2 & 2 & \\
\hline reflns collcd & 37138 & 30304 & 80738 & 37077 & 54165 & 48058 & 111016 & 73197 \\
\hline indept reflns & 2579 & 2060 & 5281 & 3077 & 3122 & 3342 & 7343 & 7741 \\
\hline obsd reflns $[I>2 \sigma(I)]$ & 1928 & 1954 & 4504 & 2894 & 2753 & 3045 & 6344 & 6157 \\
\hline$R_{\text {int }}$ & 0.060 & 0.069 & 0.030 & 0.086 & 0.036 & 0.042 & 0.069 & 0.050 \\
\hline params refined & 185 & 154 & 237 & 218 & 218 & 237 & 500 & 519 \\
\hline$R_{1}$ & 0.019 & 0.021 & 0.025 & 0.034 & 0.045 & 0.026 & 0.025 & 0.040 \\
\hline$w R_{2}$ & 0.043 & 0.042 & 0.059 & 0.091 & 0.115 & 0.056 & 0.053 & 0.088 \\
\hline$\Delta \rho_{\min }\left(\mathrm{e} \AA^{-3}\right)$ & -1.10 & -1.70 & -2.03 & -1.54 & -1.84 & -0.87 & -1.78 & -1.04 \\
\hline \multirow[t]{2}{*}{$\Delta \rho_{\max }\left(\mathrm{e} \AA^{-3}\right)$} & 0.75 & 0.85 & 1.73 & 2.91 & 2.71 & 1.46 & 2.36 & 0.71 \\
\hline & 9 & 10 & 11 & 12 & 13 & 14 & 15 & 16 \\
\hline $\begin{array}{l}\text { chemical formula } \\
M\left(\mathrm{~g} \mathrm{~mol}^{-1}\right)\end{array}$ & $\begin{array}{l}\mathrm{C}_{34} \mathrm{H}_{41} \mathrm{~N}_{2} \mathrm{O}_{16.5} \mathrm{U}_{2} \\
1217.75\end{array}$ & $\begin{array}{l}\mathrm{C}_{34} \mathrm{H}_{40} \mathrm{~N}_{2} \mathrm{O}_{16} \mathrm{U}_{2} \\
1208.74\end{array}$ & $\begin{array}{l}\mathrm{C}_{34} \mathrm{H}_{40} \mathrm{~N}_{2} \mathrm{O}_{16} \mathrm{U}_{2} \\
1208.74\end{array}$ & $\begin{array}{l}\mathrm{C}_{34} \mathrm{H}_{44} \mathrm{~N}_{7} \mathrm{O}_{16.5} \mathrm{U}_{2} \\
1286.79\end{array}$ & $\begin{array}{l}\mathrm{C}_{68} \mathrm{H}_{60} \mathrm{O}_{16} \mathrm{P}_{2} \mathrm{U}_{2} \\
1671.16\end{array}$ & $\begin{array}{l}\mathrm{C}_{78} \mathrm{H}_{64} \mathrm{O}_{16} \mathrm{P}_{2} \mathrm{U}_{2} \\
1795.29\end{array}$ & $\begin{array}{l}\mathrm{C}_{51} \mathrm{H}_{52} \mathrm{NO}_{17} \mathrm{PU}_{2} \\
1457.96\end{array}$ & $\begin{array}{l}\mathrm{C}_{51} \mathrm{H}_{50} \mathrm{NO}_{16} \mathrm{PU}_{2} \\
1439.95\end{array}$ \\
\hline cryst syst & Triclinic & Triclinic & Orthorhombic & Monoclinic & Triclinic & Monoclinic & Triclinic & Triclinic \\
\hline space group & $P_{\overline{1}}$ & $P_{\overline{1}}$ & Pna $2_{1}$ & $C c$ & $P_{\overline{1}}$ & $P 2_{1} / n$ & $P_{\overline{1}}$ & \\
\hline$a(\AA))$ & $11.0491(5)$ & 11.9884(4) & $11.7580(7)$ & $26.7267(12)$ & $10.5162(5)$ & $11.2905(5)$ & $10.3991(6)$ & $10.9871(6)$ \\
\hline$b(\AA$ & $11.4663(6)$ & $12.3618(5)$ & $12.2222(4)$ & $15.2891(3)$ & $11.4171(6)$ & $22.4381(12)$ & $12.9692(10)$ & $18.7607(13)$ \\
\hline$c(\AA)$ & $16.0160(8)$ & $14.1995(6)$ & $27.2916(15)$ & $20.4990(9)$ & $14.0450(7)$ & $13.5908(7)$ & $20.1775(14)$ & $25.6024(19)$ \\
\hline$\alpha\left({ }^{\circ}\right)$ & $98.882(3)$ & $71.281(2)$ & 90 & 90 & $90.108(3)$ & 90 & $76.166(4)$ & $88.907(3)$ \\
\hline$\beta\left(^{\circ}\right)$ & $106.200(3)$ & $76.439(2)$ & 90 & 97.072(2) & 97.901(3) & 104.129(3) & $89.632(4)$ & $85.983(4)$ \\
\hline$\gamma\left({ }^{\circ}\right)$ & $90.460(3)$ & $86.406(2)$ & 90 & 90 & $96.558(3)$ & 90 & $84.832(4)$ & $74.655(4)$ \\
\hline$V\left(\AA^{3}\right)$ & $1922.38(17)$ & 1937.29(13) & $3922.0(3)$ & $8312.7(5)$ & $1659.10(14)$ & $3338.9(3)$ & 2631.3(3) & $5076.7(6)$ \\
\hline Z & 2 & 2 & 4 & 8 & 1 & 2 & 2 & 4 \\
\hline reflns collcd & 101790 & 101426 & 93641 & 165957 & 80853 & 166159 & 135469 & 138934 \\
\hline indept reflns & 7296 & 7342 & 9666 & 15444 & 6265 & 6337 & 9989 & 19224 \\
\hline obsd reflns $[I>2 \sigma(I)]$ & 6362 & 6528 & 7841 & 14473 & 5694 & 5160 & 7488 & 13527 \\
\hline$R_{\text {int }}$ & 0.060 & 0.055 & 0.048 & 0.068 & 0.061 & 0.068 & 0.076 & 0.085 \\
\hline params refined & 500 & 524 & 492 & 1075 & 422 & 442 & 652 & 1286 \\
\hline$R_{1}$ & 0.030 & 0.027 & 0.036 & 0.040 & 0.025 & 0.032 & 0.033 & 0.074 \\
\hline$w R_{2}$ & 0.070 & 0.061 & 0.076 & 0.104 & 0.060 & 0.067 & 0.065 & 0.156 \\
\hline$\Delta \rho_{\min }\left(\mathrm{e} \AA^{-3}\right)$ & -2.16 & -2.34 & -1.80 & -1.40 & -1.24 & -1.14 & -1.32 & -2.85 \\
\hline$\Delta \rho_{\max }\left(\mathrm{e} \AA^{-3}\right)$ & 3.10 & 1.96 & 0.79 & 1.04 & 1.34 & 1.37 & 1.42 & 2.27 \\
\hline
\end{tabular}




\section{Results and discussion}

Synthesis. All complexes were synthesized under solvo-hydrothermal conditions at a temperature of $140{ }^{\circ} \mathrm{C}$. The organic cosolvent used in most syntheses was $\mathrm{N}, \mathrm{N}$ dimethylformamide (DMF, complexes 7-11 and 13-16), which results in dimethylammonium cations formed in situ from DMF hydrolysis being included in the final compound in all but two cases (13 and 14). Acetonitrile was used in the syntheses of complexes 1, 2, and 12 and is present as a free molecule in the structures of $\mathbf{1}$ and 12. Finally, the solvents $N$-methyl-2pyrrolidone (NMP, complexes 4 and 5) and $N, N^{\prime}$-dimethylpropyleneurea (DMPU, complexes 3 and 6) are in all cases included in the final compound as coligands, a usual outcome for NMP ${ }^{19,20}$ whereas few cases of uranyl bonding to DMPU are known. ${ }^{21-23}$ Where the intention was to synthesize a neutral complex including a coordinated solvent molecule, the uranyl $/ \mathrm{H}_{2} \mathrm{pda}$ ratio in the synthesis was $1: 1$, but this ratio is found in the crystallized product for complexes 3-6 only, since DMF is not present in $\mathbf{7}$ and $\mathbf{1 0}$ other than as its degradation product, dimethylammonium, and the ratio in these complexes is $2: 3$ accordingly. In all other cases, the uranyl/ $\mathrm{H}_{2}$ pda ratio in the synthesis was 7:10 in order to favour the formation of an anionic species and inclusion of structure-directing counterions, and the expected 2:3 ratio is found indeed in all the resulting complexes, except for $\mathbf{1}$ and $\mathbf{2}$ which are neutral 1:1 species. It thus appears that, on the whole and in spite of the inherent unpredictability of solvo-hydrothermal methods, the stoichiometry of the complexes formed with these ligands can be controlled to a certain degree.

Crystal Structures. As is by far most common for uranyl complexes with carboxylate ligands, the uranium atom environment in all complexes 1-16 has either pentagonal or hexagonal bipyramidal geometry. The carboxylato groups are most often chelating in $\kappa^{2} O, O^{\prime}$ mode, with formation of a four-membered chelate ring, or bonded to one or two metal cations 
through individual oxygen atoms, the coordination bond lengths being somewhat smaller in the latter mode; some cases of mixed chelation and bridging are also encountered. Overall, the UO bond lengths in the present series do not depart significantly from the values commonly observed. The $\mathrm{U}-\mathrm{O}$ (oxido) bond lengths are in the range of 1.74-1.80 $\AA$ (all complexes considered), and the $\mathrm{U}-\mathrm{O}$ (carboxylato) bond lengths vary within the $2.42-2.57 \AA$ and $2.30-$ $2.43 \AA$ ranges for chelating and monodentate/bridging groups, respectively; being unexceptional, these distances will not be further discussed.

Although they involve different isomeric forms of the ligand and are not isomorphous, the two complexes $\left[\mathrm{UO}_{2}(1,2-\right.$ pda) $] \cdot \mathrm{CH}_{3} \mathrm{CN}$ (1) and $\left[\mathrm{UO}_{2}(1,3-\right.$ pda) $]$ (2) have many points in common. Both are neutral, homometallic and homoleptic species, the first to be obtained with $\mathrm{pda}^{2-}$ ligands. The two independent uranium atoms in $\mathbf{1}$ are located on inversion centers, and each of them is chelated by two carboxylato groups in trans positions and bound to two additional carboxylato oxygen atoms, the environment being hexagonal bipyramidal (Figure 1). One of the oxygen atoms of each chelating group bridges atoms $\mathrm{U} 1$ and $\mathrm{U} 2$, so that the coordination polyhedra of the uranium atoms have a common edge, and chains of doubly bridged uranyl cations run along [100]. The 1,2-pda ${ }^{2-}$ ligand adopts a chiral pseudo- $C_{2}$ conformation with the carboxylato groups pointing on either side of the aromatic ring plane (a form denoted "trans" in the following), and they are connected to four metal atoms in the bis$\mu_{2}-\kappa^{1} O: \kappa^{2} O, O^{\prime}$ mode. The chains are thus assembled into a diperiodic, uninodal net parallel to (010), which has the $\left\{4^{4} \cdot 6^{2}\right\}$ point symbol and the common sql topological type (Figure 2). This assembly displays prominently protruding aromatic rings on both sides, which are involved in an interlayer parallel-displaced $\pi$-stacking interaction [centroid $\cdots$ centroid distance $3.987(2) \AA$, dihedral angle $0.03(19)^{\circ}$, slippage $\left.1.41 \AA\right]$. Examination of the Hirshfeld surface (HS), ${ }^{24}$ calculated on the asymmetric unit using CrystalExplorer (Version 3.1) ${ }^{25}$ reveals the presence of $\mathrm{CH} \cdots \mathrm{O}$ hydrogen bonds, ${ }^{26,27}$ involving an aromatic proton and a uranyl oxido group or 
methylenic protons and carboxylato groups $[\mathrm{H} \cdots \mathrm{O}$ distances $2.48-2.57 \AA, \mathrm{C}-\mathrm{H} \cdots \mathrm{O}$ angles $123-$ $\left.161^{\circ}\right]$, as well as a $\mathrm{CH} \cdots \mathrm{N}$ bond involving a methylenic proton and acetonitrile $[\mathrm{H} \cdots \mathrm{N} 2.68 \AA$, $\mathrm{C}-\mathrm{H} \cdots \mathrm{N} 146^{\circ}$ ]. The Kitaigorodski packing index (KPI, calculated with PLATON ${ }^{15}$ ) of 0.70 indicates a compact packing with no solvent-accessible free space.

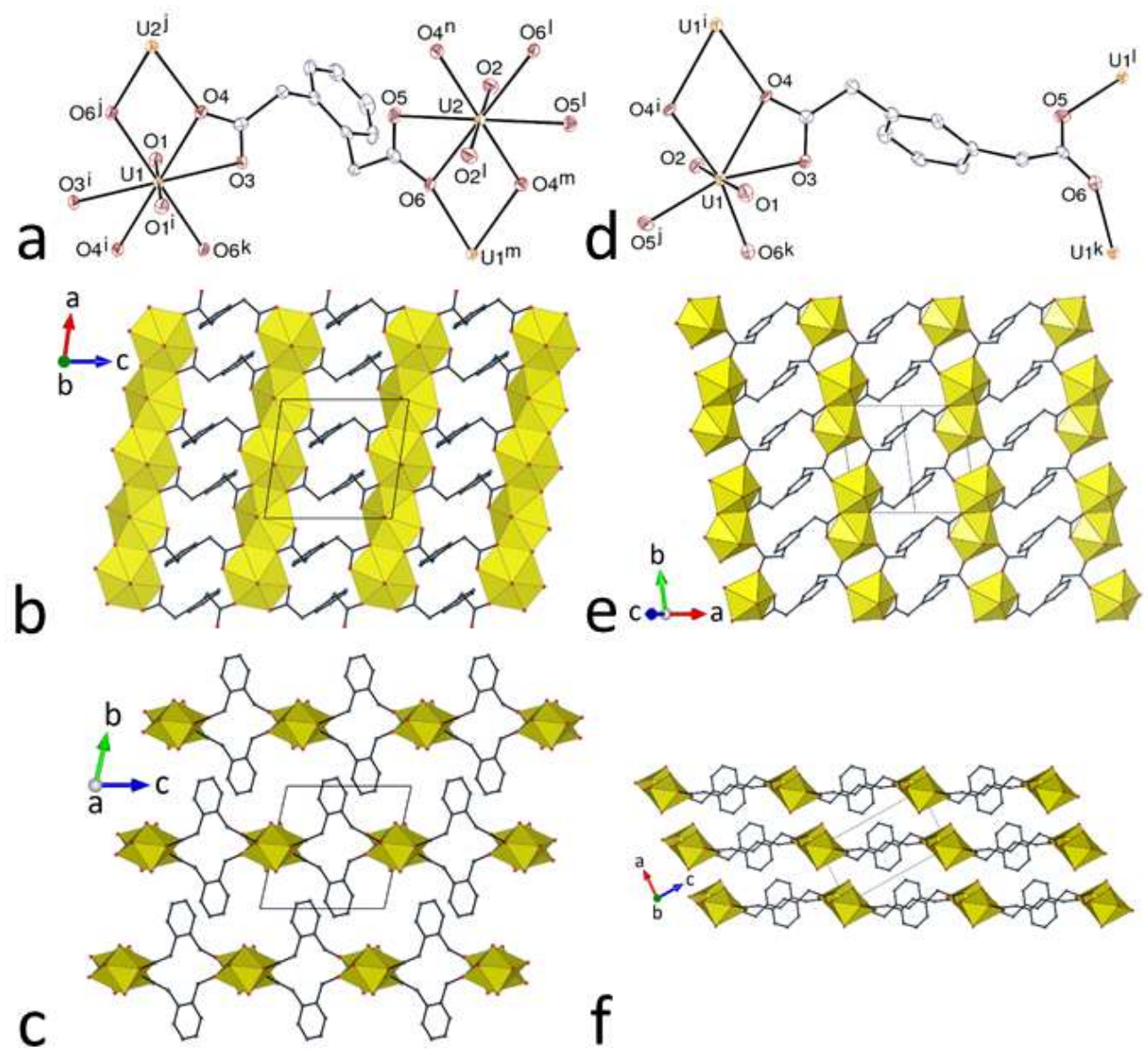

Figure 1. (a) View of compound 1 with solvent molecule and hydrogen atoms omitted. Symmetry codes: $i=1-$ $x, 1-y, 2-z ; \mathrm{j}=x, y, z+1 ; \mathrm{k}=1-x, 1-y, 1-z ; 1=2-x, 1-y,-z ; \mathrm{m}=x, y, z-1 ; \mathrm{n}=2-x, 1-y, 1-z .(\mathrm{b})$ View of the 2D network in 1 showing uranium coordination polyhedra. (c) Packing in 1 with layers viewed edgeon. (d) View of compound 2 with hydrogen atoms omitted. Symmetry codes: $\mathrm{i}=-x,-y, 2-z ; \mathrm{j}=x-1, y, z+1 ; \mathrm{k}$ $=1-x, 1-y, 1-z ; 1=x+1, y, z-1$. (e) View of the 2D network in 2. (f) Packing in 2 with layers viewed edgeon. 

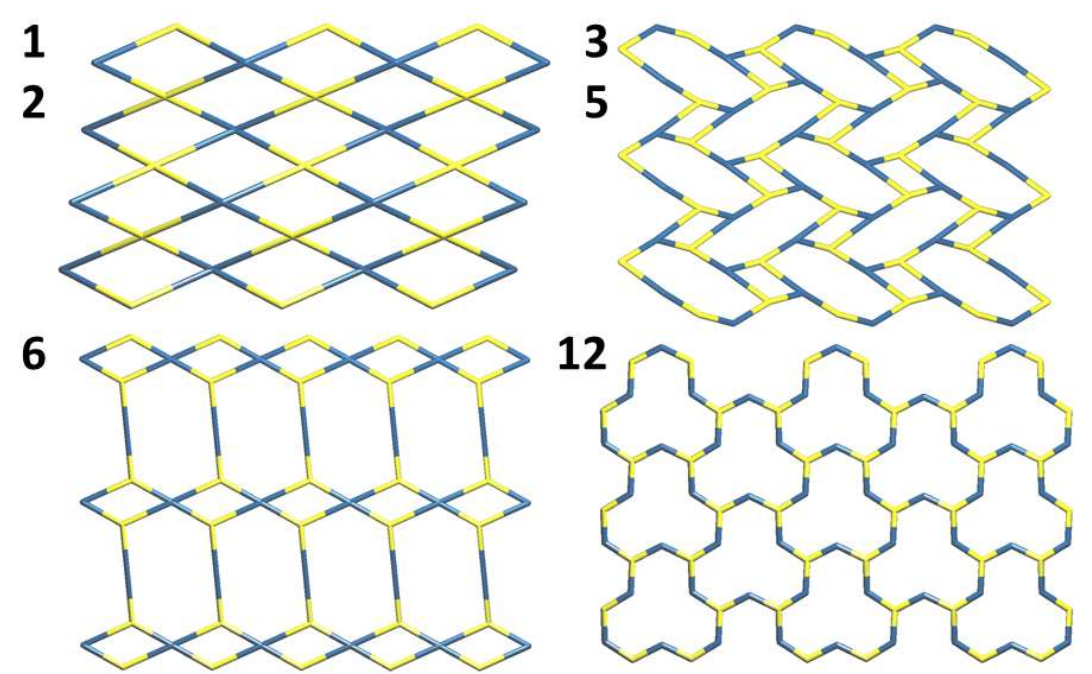

Figure 2. Nodal representation of the diperiodic networks in complexes 1, 2, 3, 5, 6 and 12 (uranium, yellow; dicarboxylate ligand, blue).

The unique uranium cation in $\mathbf{2}$ is chelated by one carboxylato group and bound to three additional carboxylato oxygen donors from three different ligands, its environment being pentagonal bipyramidal (Figure 1). One of the atoms of the chelating group is also bridging, thus forming centrosymmetric dimeric units with the two uranium coordination polyhedra sharing a common edge. The 1,3-pda ${ }^{2-}$ ligand assumes the same pseudo- $C_{2}$ trans conformation as $1,2-\mathrm{pda}^{2-}$ in $\mathbf{1}$, with the two arms oriented to opposite sides of the aromatic ring plane but, while one carboxylato group is coordinated in the same $\mu_{2}-\kappa^{1} O: \kappa^{2} O, O^{\prime}$ mode as in $\mathbf{1}$, the second is bridging in the syn/anti $\mu_{2}-\kappa^{1} O: \kappa^{1} O^{\prime}$ mode. Here also, metal and ligand are four-coordinated (4-c) nodes and a diperiodic network is formed, parallel to (101), which, in spite of the coordination modes of uranyl and ligand being different from those in $\mathbf{1}$, has the same sql topological type. Due to the more elongated shape of the ligand, the layers in $\mathbf{2}$ are much flatter than in $\mathbf{1}$, and no interlayer $\pi$-stacking interaction is present. Both intra- and interlayer $\mathrm{CH} \cdots \mathrm{O}$ hydrogen bonds unite methylenic protons to oxido and carboxylato groups $[\mathrm{H} \cdots \mathrm{O}$ distances 2.49-2.62 $\AA, \mathrm{C}-\mathrm{H} \cdots \mathrm{O}$ angles $129-135^{\circ}$ ], and the packing is quite compact (KPI 0.72). 
The four complexes of 1:1:1 uranyl/dicarboxylate/solvent stoichiometry, [ $\mathrm{UO}_{2}(1,2-$ pda)(DMPU)] (3), [UO $2(1,3-p d a)(N M P)](4),\left[\mathrm{UO}_{2}(1,4-\mathrm{pda})(\mathrm{NMP})\right](\mathbf{5})$, and $\left[\mathrm{UO}_{2}(1,4-\right.$ pda)(DMPU)] (6) contain a coordinated NMP or DMPU molecule and cover the range of all three isomers of the ligand. As a common feature, the unique uranium cation in all of them is in a pentagonal bipyramidal environment, being chelated by one carboxylato group and bound to two more carboxylato donors and the solvent molecule (Figure 3). The 1,2-pda ${ }^{2-}$ ligand in 3 has one arm in the plane of the aromatic ring, with the $\mathrm{COO}^{-}$group straddling the plane, and the other directed sideways, while the 1,3- and 1,4-pda ${ }^{2-}$ ligands in $\mathbf{4}$ and $\mathbf{5}$ are in the trans conformation. In $\mathbf{6}$, one of the two centrosymmetric ligands (containing $\mathrm{O} 3$ and $\mathrm{O} 4$ ) also has the latter conformation, but the other (containing O5 and O6) is much flatter, the two arms being only slightly displaced on either side of the ring plane. The ligand connectivity is identical in 3, 4 and 5, with one carboxylato group $\kappa^{2} O, O^{\prime}$-chelating and the other syn/anti $\mu_{2}-\kappa^{1} O: \kappa^{1} O^{\prime}$ bridging. These two modes are distinct in the two independent ligands in $\mathbf{6}$, one being bischelating and the other bis-bridging. A common feature of all four complexes is the presence of centrosymmetric, dinuclear, doubly-bridged entities, the uranium coordination polyhedra sharing however no edge or vertex. The $\mathrm{U}-\mathrm{O}$ bond lengths with the monodentate solvent molecules are 2.340(2) and 2.305(3) $\AA$ in the case of DMPU in 3 and 6 [2.288(4)-2.363(2) $\AA$ in previous examples ${ }^{21-23}$ ] and 2.378(4) and 2.355(7) $\AA$ in the case of NMP in 4 and $\mathbf{5}$ $\left[2.313(8)-2.438(6) \AA\right.$ in previous examples $\left.{ }^{19,20,28}\right]$. These distances are significantly shorter than those of the chelating carboxylates and comparable to those of the bridging carboxylates, indicating that DMPU and NMP are ligands capable of competing with acetate groups for binding to $\mathrm{U}^{\mathrm{VI}}$, thereby perhaps providing a steric influence to prevent acetate poly-chelation. In complexes 3, 4 and 5, both metal and ligand are three-coordinated (3-c) nodes, but the coordination polymers formed are nevertheless different (Figure 4). In $\mathbf{3}$ and $\mathbf{5}$, uninodal 2D networks are formed, parallel to (101) and (10-2), respectively, which have both the $\left\{4.8^{2}\right\}$ 

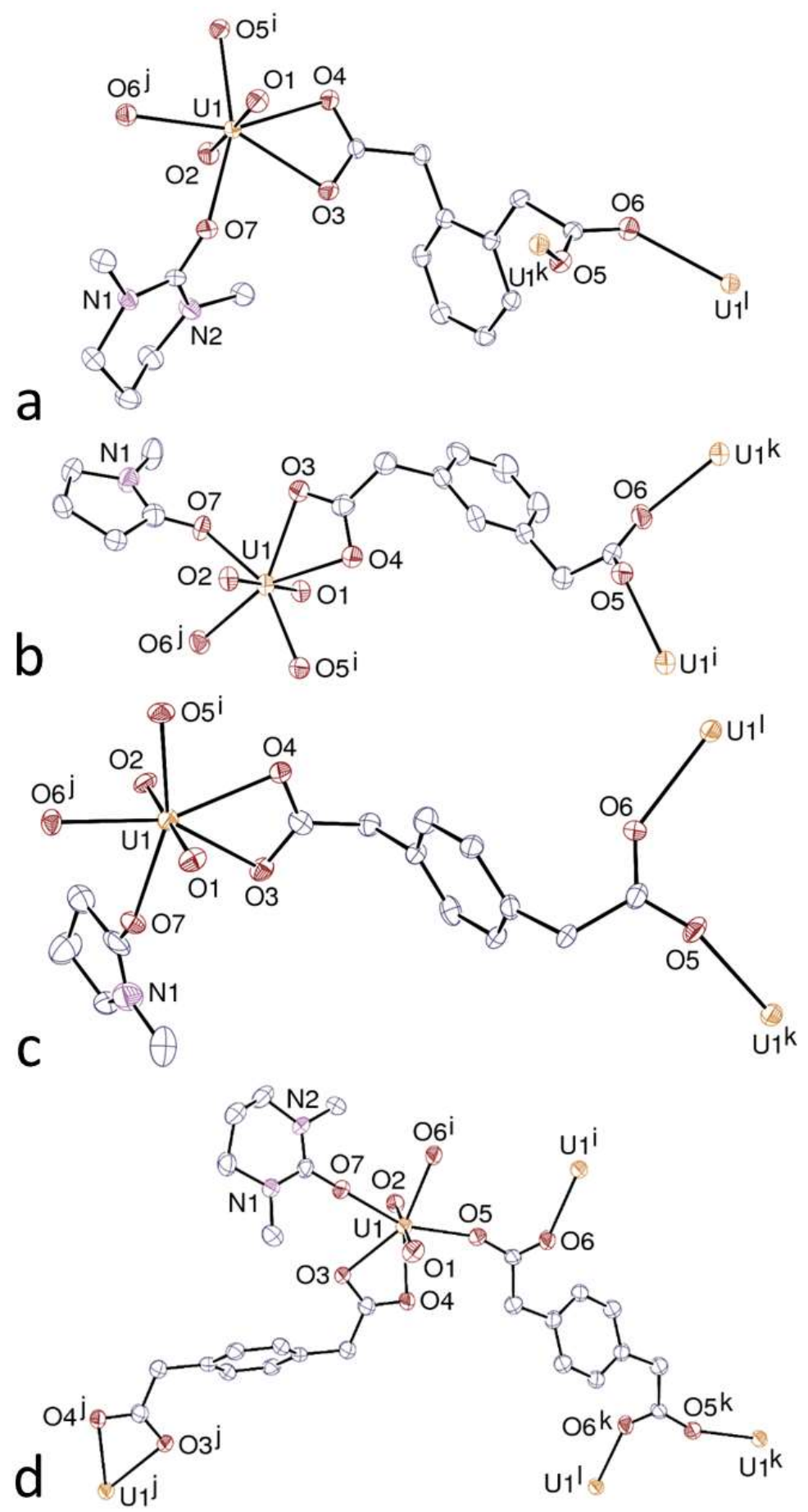

Figure 3. Views of compounds 3 (a), 4 (b), 5 (c), and $\mathbf{6}$ (d) with hydrogen atoms omitted. Symmetry codes: $\mathbf{3} i=$ $1 / 2-x, y-1 / 2,3 / 2-z ; \mathrm{j}=x+1 / 2,3 / 2-y, z-1 / 2 ; \mathrm{k}=1 / 2-x, y+1 / 2,3 / 2-z ; 1=x-1 / 2,3 / 2-y, z+1 / 2 ; 4 \mathrm{i}=1$ $-x, 2-y, 1-z ; \mathrm{j}=x+1, y-1, z ; \mathrm{k}=x-1, y+1, z ; \mathbf{5} \mathrm{i}=1-x, y+1 / 2,1 / 2-z ; \mathrm{j}=x+1,1 / 2-y, z+1 / 2 ; \mathrm{k}=1-$ $x, y-1 / 2,1 / 2-z ; 1=x-1,1 / 2-y, z-1 / 2 ; 6 \mathrm{i}=1-x, 1-y, 1-z ; \mathrm{j}=2-x,-y,-z ; \mathrm{k}=-x, 1-y,-z ; 1=x-1, y$, $z-1$. 

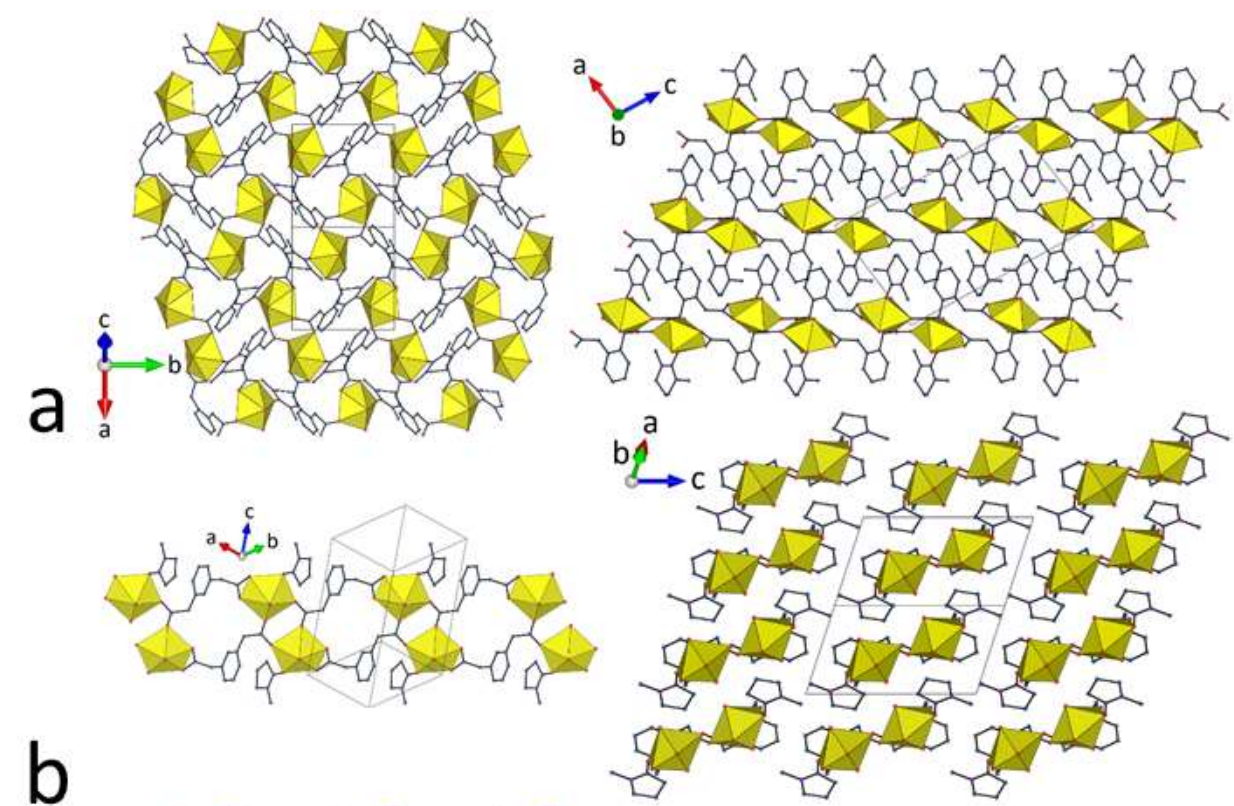

b
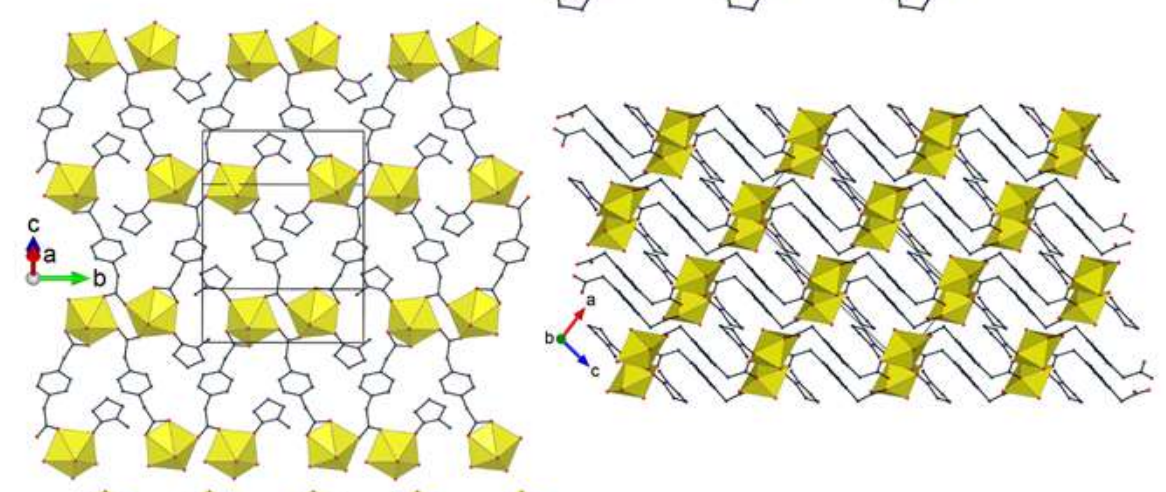

\section{C}
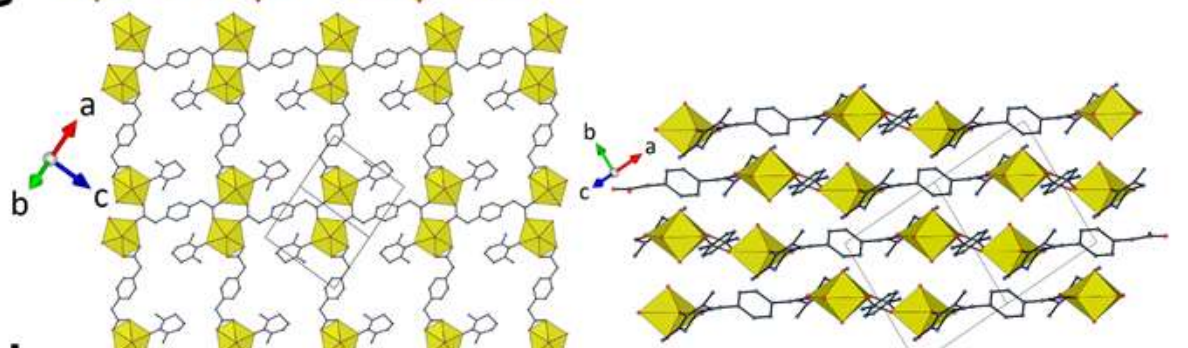

Figure 4. (a) View of the 2D assembly (left) and the packing with layers edge-on (right) in compound 3. (b) View of the $1 \mathrm{D}$ polymer (left) and the packing with chains end-on (right) in compound 4. (c) View of the $2 \mathrm{D}$ assembly (left) and the packing with layers edge-on (right) in compound 5. (d) View of the 2D assembly (left) and the packing with layers edge-on (right) in compound 6.

point symbol and the common fes topological type (Figure 2); alternatively, if the dinuclear units are considered as single, 4-c nodes, the topological type is sql, albeit one in which the ligands are simple links and not 4-c nodes as in $\mathbf{1}$ and $\mathbf{2}$. The layers in $\mathbf{3}$ are slightly puckered, 
with the 1,2-pda ${ }^{2-}$ aromatic rings and the DMPU molecules projecting from both sides, while the layers in $\mathbf{5}$ have a double-sawtooth profile, this profile reflecting the opposed orientation of the acetate substituents of the pseudo-centrosymmetric 1,4-pda ${ }^{2-}$ ligand on the phenyl ring, and the NMP molecules do not protrude out of the sheet. There is no $\pi$-stacking interaction in both compounds, but one DMPU/NMP methylenic proton is involved in a possibly strong interlayer $\mathrm{CH} \cdots \pi$ interaction $\left[\mathrm{H} \cdots\right.$ centroid distance 2.67 and $2.85 \AA, \mathrm{C}-\mathrm{H} \cdots$ centroid angle 129 and $151^{\circ}$ in $\mathbf{3}$ and 5, respectively], and, as usual, $\mathrm{CH} \cdots \mathrm{O}$ hydrogen bonds are also present. In contrast, a 1D polymer only is formed with the $1,3-\mathrm{pda}^{2-}$ ligand in $\mathbf{4}$, which runs parallel to [110] and has a ribbon-like shape with the NMP methyl groups directed outward on both edges (Figure 4). There is no $\pi$-stacking interaction in this case either, but interlayer $\mathrm{CH} \cdots \mathrm{O}$ hydrogen bonds $\left[\mathrm{H} \cdots \mathrm{O}\right.$ distances 2.39 and $2.54 \AA, \mathrm{C}-\mathrm{H} \cdots \mathrm{O}$ angles 158 and $\left.128^{\circ}\right]$ and one $\mathrm{CH} \cdots \pi$ interaction $\left[\mathrm{H} \cdots\right.$ centroid distance $2.96 \AA, \mathrm{C}-\mathrm{H} \cdots$ centroid angle $\left.132^{\circ}\right]$ are found. The metal centres in complex 6 are still 3-c nodes, but the bis-bridging 1,4-pda ${ }^{2-}$ ligand is a 4-c node and the bischelating one is a simple link. The binodal 3,4-coordinated (3,4-c) 2D network formed, parallel to (12ī), has the point symbol $\left\{4.6^{2}\right\}_{2}\left\{4^{2} \cdot 6^{2} \cdot 8^{2}\right\}$ and the topological type 3,4L13 (Figure 2) previously encountered in other uranyl carboxylato complexes, with the metal and ligand roles sometimes reversed. ${ }^{20,23}$ Here also, the topology is sql if the dinuclear dimers are considered as 4-c nodes. The layers here do not depart much from planarity and the DMPU molecules occupy the large oblong rings formed $(\sim 15 \times 9 \AA)$. No $\pi$-stacking interaction is present, but methyl and methylene protons of DMPU form intra- and interlayer $\mathrm{CH} \cdots \mathrm{O}$ hydrogen bonds $[\mathrm{H} \cdots \mathrm{O}$ distances 2.51 and $2.60 \AA, \mathrm{C}-\mathrm{H} \cdots \mathrm{O}$ angles 141 and $\left.140^{\circ}\right]$ and $\mathrm{CH} \cdots \pi$ interactions $[\mathrm{H} \cdots$ centroid distances 2.77 and $2.87 \AA, \mathrm{C}-\mathrm{H} \cdots$ centroid angles 124 and $\left.152^{\circ}\right]$. With KPIs in the range of $0.70-0.73$, the packings in 3-6 are quite compact and no solvent-accessible space is present. 
The two complexes $\left[\mathrm{H}_{2} \mathrm{NMe}_{2}\right]_{2}\left[\left(\mathrm{UO}_{2}\right)_{2}(1,2-\mathrm{pda})_{3}\right] \cdot \mathrm{H}_{2} \mathrm{O}(7)$ and $\left[\mathrm{H}_{2} \mathrm{NMe}_{2}\right]_{2}\left[\left(\mathrm{UO}_{2}\right)_{2}(1,2-\right.$ pda $\left.)_{3}\right] \cdot 3 \mathrm{H}_{2} \mathrm{O}(\mathbf{8})$, which involve the same ligand isomer, counterion, and stoichiometry, present close similarities and will be described together. In both cases, the two independent uranium cations are chelated by three carboxylato groups (hexagonal bipyramidal environment), and the three independent, bis-chelating 1,2-pda ${ }^{2-}$ ligands are in the trans conformation. The metal centres are thus 3-c nodes and the ligands are simple links, and the double-stranded 1D coordination polymers formed are ladder-like and run along the [100] direction (Figure 5). A given double stranded polymer contains only one enantiomeric form of the ligand but it is
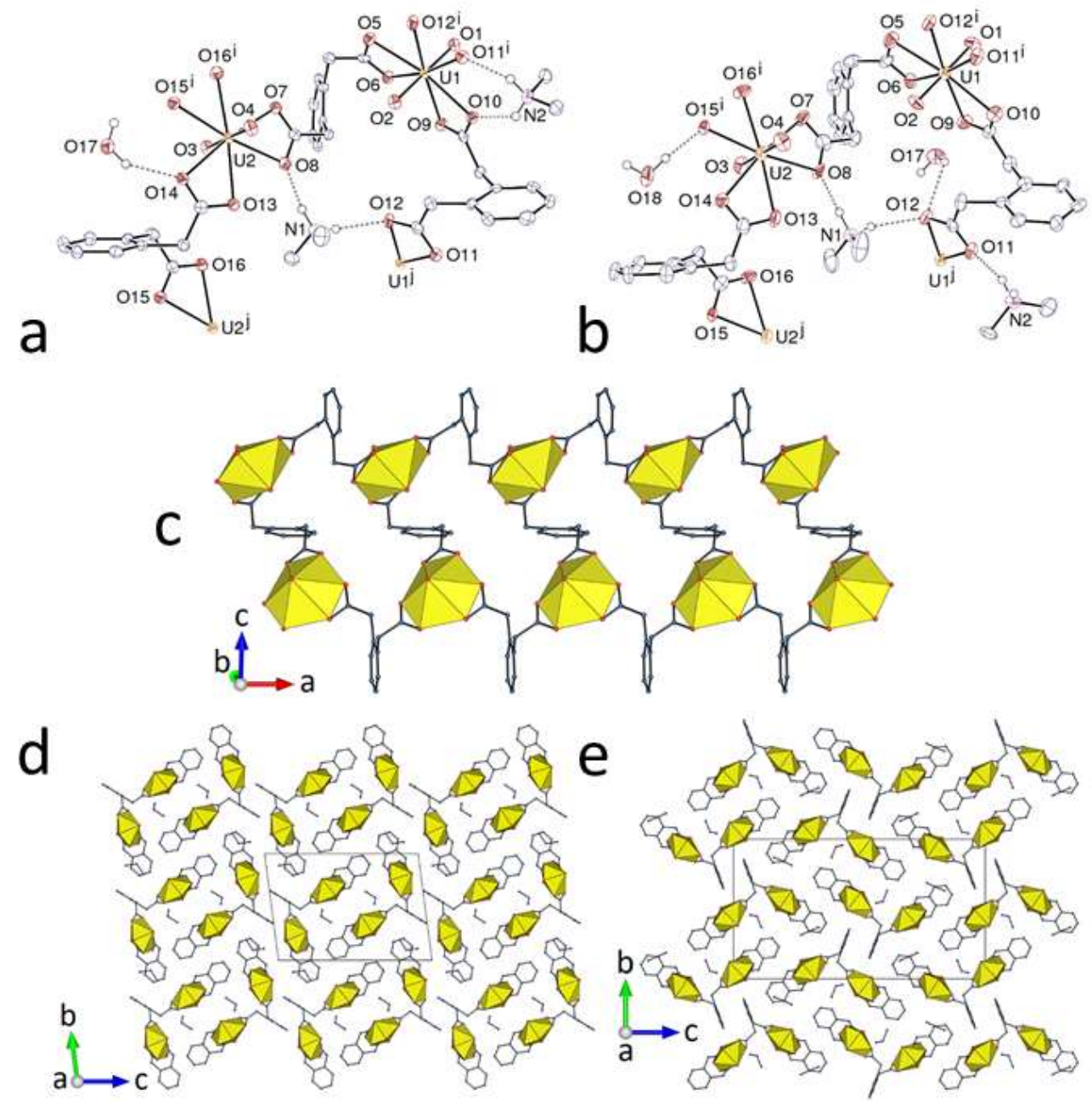

Figure 5. Views of compounds 7 (a) and $\mathbf{8}$ (b), with carbon-bound hydrogen atoms omitted and hydrogen bonds shown as dashed lines. Symmetry codes: $\mathrm{i}=x+1, y, z ; \mathrm{j}=x-1, y, z$ for both. View of the 1D polymer in 8 (c). Packing in 7 (d) and $\mathbf{8}$ (e), with chains viewed end-on. 
closely associated with another which is its image by inversion, so that the overall lattice is racemic. Since the polymer has a curved section, the two chains facing each other through their concave side define a cavity which contains the $\mathrm{H}_{2} \mathrm{NMe}_{2}{ }^{+}$counterions. Each of the latter is however hydrogen bonded to carboxylato groups of one chain only [ $\mathrm{N} \cdots \mathrm{O}$ distances $2.735(5)-$ 3.244(4) $\AA, \mathrm{N}-\mathrm{H} \cdots \mathrm{O}$ angles $128-174^{\circ}$ ], as are also the water molecules. The aromatic rings of the central ligands in the chains point outside these dimeric units and, in 7, they are involved in a parallel-displaced $\pi$-stacking interaction with their counterpart in a neighbouring chain along the [001] direction [centroid $\cdots$ centroid distance 3.650(2) $\AA$, dihedral angle $0^{\circ}$ ], while such contacts are absent in $\mathbf{8}$ due to too large a shift of the chains with respect to one another along [100]. The fact that these two structures are virtually identical whether or not $\pi$-stacking interactions are present is an indication of the minor role they play, in keeping with their nearnonappearance in the Hirshfeld surfaces. As usual, several $\mathrm{CH} \cdots \mathrm{O}$ hydrogen bonds involving methylene and methyl groups as donors and oxido, carboxylato and free water as acceptors are present in both compounds [ $\mathrm{H} \cdots \mathrm{O}$ distances $2.33-2.59 \AA, \mathrm{C}-\mathrm{H} \cdots \mathrm{O}$ angles $\left.117-169^{\circ}\right]$, and the KPIs of 0.70 and 0.69 are indicative of compact packings.

Again including dimethylammonium counterions, but with the $1,3-\mathrm{pda}^{2-}, 1,4-\mathrm{pda}^{2-}$, or a mixture of 1,2- and 1,4-pda ${ }^{2-}$ ligands, the three complexes $\left[\mathrm{H}_{2} \mathrm{NMe}_{2}\right]_{2}\left[\left(\mathrm{UO}_{2}\right)_{2}(1,3-\right.$ pda $\left.)_{3}\right] \cdot 0.5 \mathrm{H}_{2} \mathrm{O}(\mathbf{9}),\left[\mathrm{H}_{2} \mathrm{NMe}_{2}\right]_{2}\left[\left(\mathrm{UO}_{2}\right)_{2}(1,4-\mathrm{pda})_{3}\right](\mathbf{1 0})$, and $\left[\mathrm{H}_{2} \mathrm{NMe}_{2}\right]_{2}\left[\left(\mathrm{UO}_{2}\right)_{2}(1,2-\right.$ pda $)(1,4-$ pda $)_{2}$ (11) display very close crystal structures. In all of them, the two independent uranium cations are chelated by three carboxylato groups, and the three independent ligands are bischelating, as in 7 and $\mathbf{8}$. The difference with the latter species however is that the 1D coordination polymers formed (parallel to [011], [112] and [001] in 9-11, respectively) are single-stranded daisychains with an alternation of single and double bridges between successive uranyl cations (Figure 6). This difference arises from the different conformation assumed by 

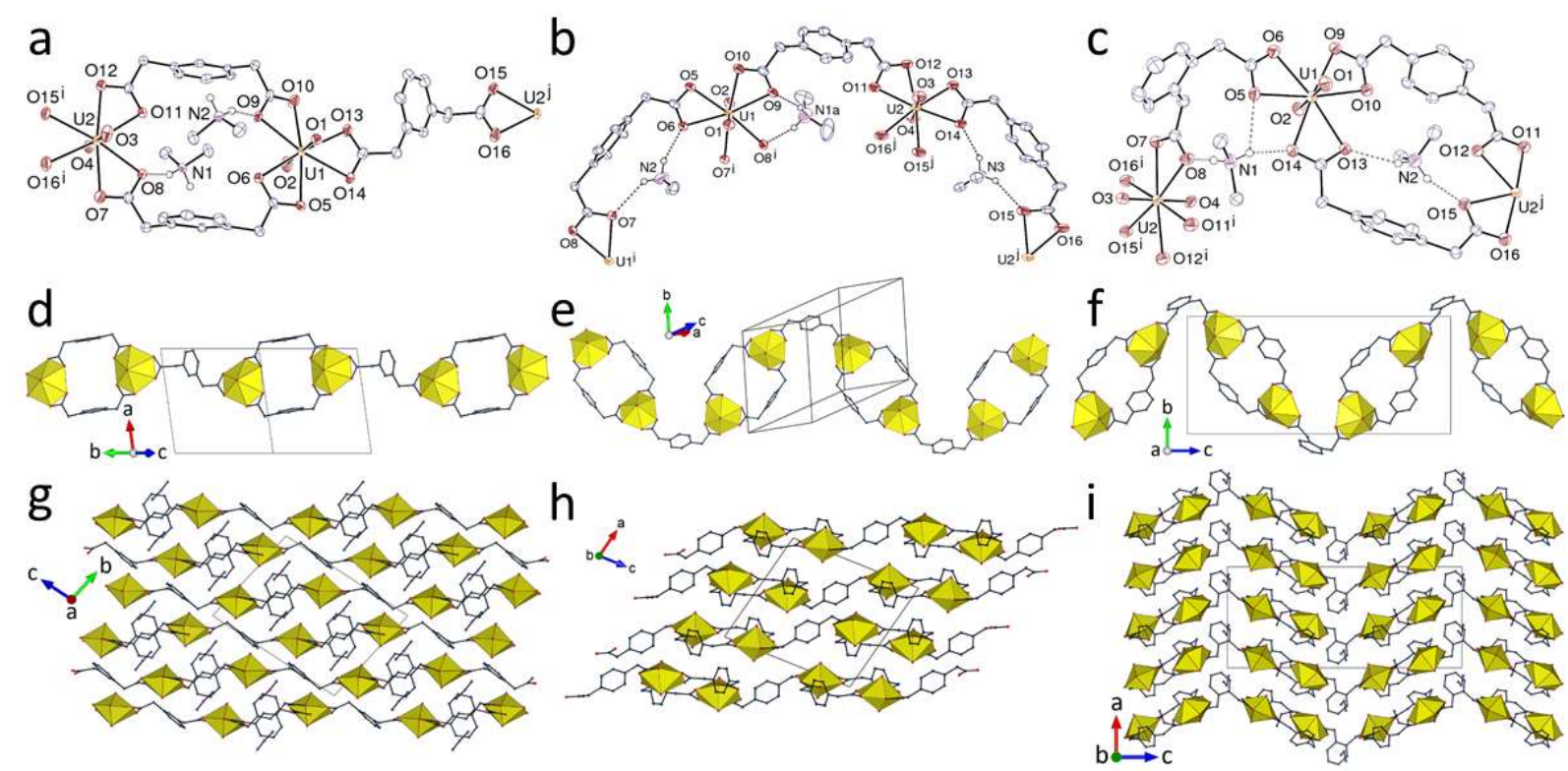

Figure 6. Views of compounds 9 (a), 10 (b), and 11 (c), with carbon-bound hydrogen atoms omitted and hydrogen bonds shown as dashed lines. Symmetry codes: $9 \mathrm{i}=x, y+1, z-1 ; \mathrm{j}=x, y-1, z+1 ; \mathbf{1 0} \mathrm{i}=1-x,-y, 2-z ; \mathrm{j}=-$ $x, 1-y,-z ; 11 \mathrm{i}=2-x,-y, z-1 / 2 ; \mathrm{j}=2-x,-y, z+1 / 2$. View of the $1 \mathrm{D}$ polymers in 9 (d), 10 (e), and 11 (f). Packing with the chains viewed side-on in $\mathbf{9}(\mathrm{g}), \mathbf{1 0}(\mathrm{h})$, and 11 (i).

the 1,3-pda ${ }^{2-}(\mathbf{9})$ or 1,4-pda ${ }^{2-}(\mathbf{1 0}$ and 11) ligands in the doubly-bridged dimeric units, which is "cis" and pincer-like, with the two arms pointing on the same side of the aromatic ring. Similar $\left(\mathrm{UO}_{2}\right)_{2}(1,4-\mathrm{pda})_{2}$ rings have previously been found as subunits in different $1 \mathrm{D}$ or $2 \mathrm{D}$ assemblies. ${ }^{9,10}$ This difference in conformation between the 1,2-pda ${ }^{2-}$ ligand in 7 and 8 and the 1,3- and 1,4-pda ${ }^{2-}$ ligands here is probably due to the reduced repulsion between the ring substituents in the latter. The 1,3-pda ${ }^{2-}$ ligands which connect these dinuclear rings in 9 are in the trans conformation, and the chains are linear as consequence, while the 1,4-pda ${ }^{2-}$ connecting ligands in $\mathbf{1 0}$ are also cis, which gives the chain a zigzag shape. In 11, the 1,2-pda ${ }^{2-}$ ligands connect the $\left(\mathrm{UO}_{2}\right)_{2}(1,4-\mathrm{pda})_{2}$ rings and they have a conformation in which one of the arms straddles the aromatic ring plane, as in complex $\mathbf{3}$, which again gives the chain a zigzag shape. It is notable that $\mathbf{1 1}$ is the second case of a complex containing both the 1,2 and 1,4 isomers, after a complex with the same stoichiometry crystallizing as a $2 \mathrm{D}$ network. ${ }^{10}$ In $\mathbf{9}$, the two 
counterions project onto the rings and are involved in hydrogen bonding with two chains, thus generating the formation of sheets $[\mathrm{N} \cdots \mathrm{O}$ distances $2.780(6)-3.151(5) \AA, \mathrm{N}-\mathrm{H} \cdots \mathrm{O}$ angles $131-$ $161^{\circ}$ ]. In $\mathbf{1 0}$ and $\mathbf{1 1}$, one counterion is included in the ring while the other is located close to the curved section of the chain. Both form hydrogen bonds with carboxylato oxygen atoms (as well

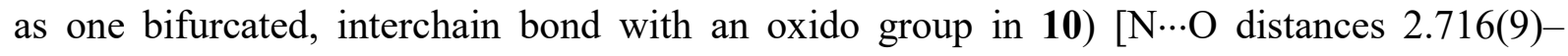
3.183(11) $\AA, \mathrm{N}-\mathrm{H} \cdots \mathrm{O}$ angles $\left.124-167^{\circ}\right]$. Only 9 displays contacts possibly indicative of a $\pi$ -

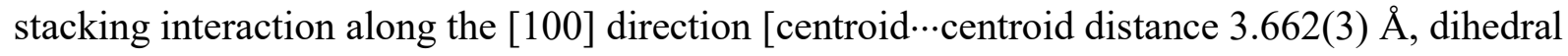
angle $2.3(2)^{\circ}$ ], but $\mathrm{CH} \cdots \mathrm{O}$ and $\mathrm{CH} \cdots \pi$ interactions are found in all three. The KPI in $\mathbf{1 1}$ is 0.67 , while disorder prevents an accurate determination in $\mathbf{9}$ and $\mathbf{1 0 .}$

Only one complex was obtained with the guanidinium counterion, $\left[\mathrm{C}\left(\mathrm{NH}_{2}\right)_{3}\right]_{2}\left[\left(\mathrm{UO}_{2}\right)_{2}(1,2-\mathrm{pda})_{3}\right] \cdot 0.5 \mathrm{H}_{2} \mathrm{O} \cdot \mathrm{CH}_{3} \mathrm{CN}$ (12). This complex crystallizes with four independent uranium atoms, all of them tris-chelated, pertaining to two independent, but nearly identical polymeric units (Figure 7). All six bis-chelating 1,2-pda ${ }^{2-}$ ligands are in the usual trans conformation and the uranyl/ligand stoichiometry is the same as in complexes $\mathbf{7}$ and $\mathbf{8}$, but the change in counterion results in a quite different coordination polymer being formed. The two independent polymers are here 2D and parallel to (001), and they alternate along the [001] direction. The uranium atoms are 3-c nodes and the ligands simple links, the point symbol being $\left\{6^{3}\right\}$ and the topological type the very common hcb (Figure 2). The arrangement of the nodes is hexagonal, but since only three aromatic rings are pointing toward the centre of each hexagonal cell, the appearance is that of a triangular arrangement, as previously found for example in a uranyl complex with 1,3-benzenedicarboxylate. ${ }^{29}$ The symmetry of the network is also reduced by the fact that each cell includes two cations and one molecule of acetonitrile in its three lobes, these moieties being strongly inclined with respect to the cell plane, and by the mixed conformations of the bridging ligands, where four are of one chirality and two are of 

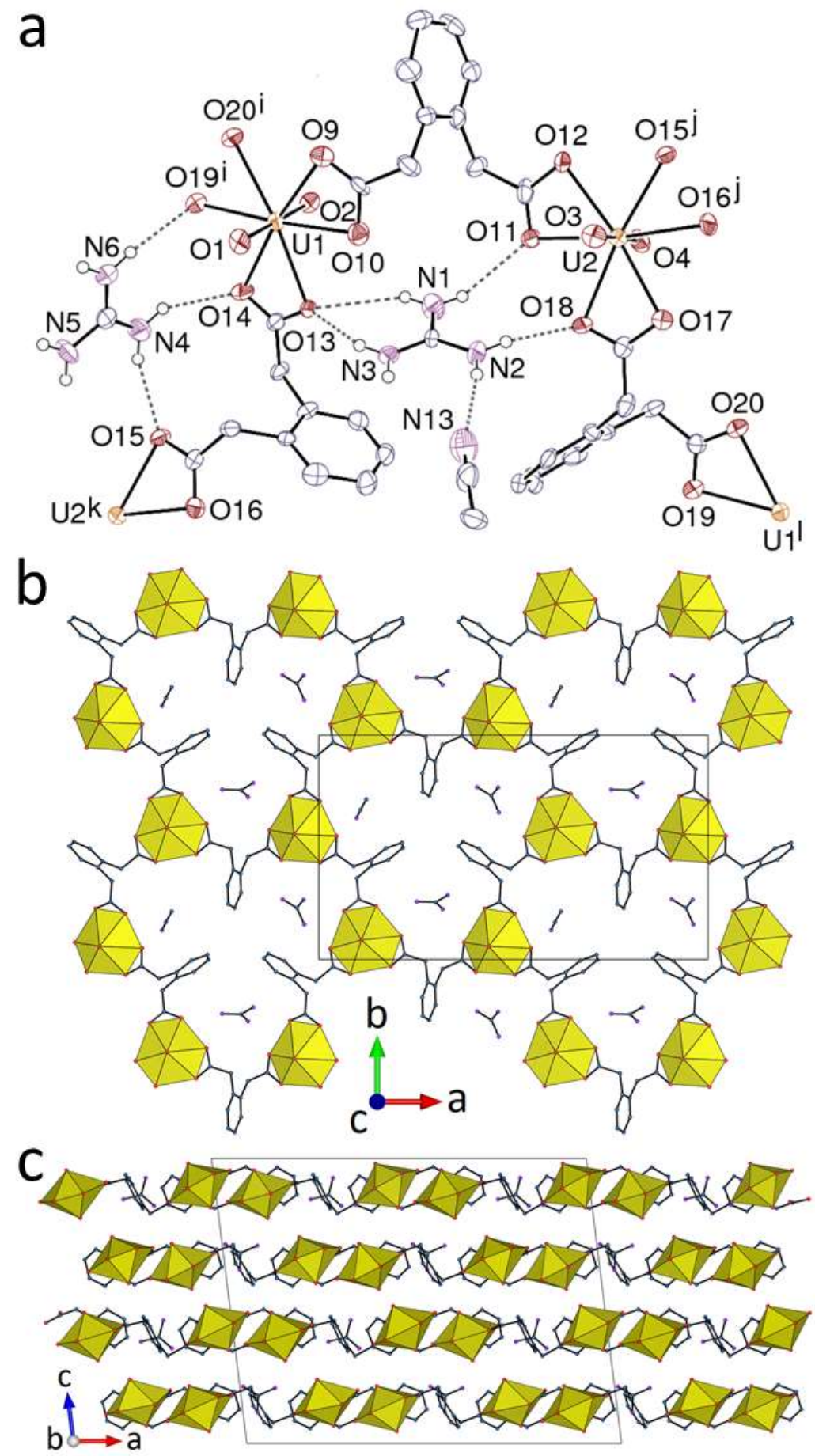

Figure 7. (a) View of one of the two independent units in compound $\mathbf{1 2}$ with carbon-bound hydrogen atoms omitted and hydrogen bonds shown as dashed lines. Symmetry codes: $\mathrm{i}=x-1 / 2, y+1 / 2, z ; \mathrm{j}=x+1 / 2, y+1 / 2, z$; $\mathrm{k}=x-1 / 2, y-1 / 2, z ; 1=x+1 / 2, y-1 / 2, z ; \mathrm{m}=x, y+1, z$. (b) View of the 2D assembly. (c) Packing with layers viewed edge-on. 
the opposite, alternating $\Delta \Delta \Lambda \Delta \Delta \Lambda$ in one sheet and $\Lambda \Lambda \Delta \Lambda \Lambda \Delta$ in the next. With their six hydrogen atoms each, the four inequivalent guanidinium cations are involved in an extended and intricate hydrogen bond network, both intra- and interlayer, with oxido, carboxylato and

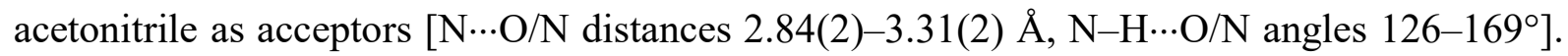
No $\pi$-stacking interaction is present, but $\mathrm{OH}$ (water) $\cdots \mathrm{O}$ and $\mathrm{CH} \cdots \mathrm{O}$ hydrogen bonds, as well as $\mathrm{NH} \cdots \pi$ interactions are found, the packing of the layers leaving not significant free space (KPI 0.68).

The last group of complexes in the present series includes four species containing phosphonium counterions, $\left[\mathrm{PPh}_{3} \mathrm{Me}\right]_{2}\left[\left(\mathrm{UO}_{2}\right)_{2}(1,3-\text { pda })_{3}\right](\mathbf{1 3}),\left[\mathrm{PPh}_{4}\right]_{2}\left[\left(\mathrm{UO}_{2}\right)_{2}(1,4-\text { pda })_{3}\right](\mathbf{1 4})$, $\left[\mathrm{PPh}_{3} \mathrm{Me}\right]\left[\mathrm{H}_{2} \mathrm{NMe}_{2}\right]\left[\left(\mathrm{UO}_{2}\right)_{2}(1,4-\mathrm{pda})_{3}\right] \cdot \mathrm{H}_{2} \mathrm{O} \quad(\mathbf{1 5}), \quad$ and $\quad\left[\mathrm{PPh}_{3} \mathrm{Me}\right]\left[\mathrm{H}_{2} \mathrm{NMe}_{2}\right]\left[\left(\mathrm{UO}_{2}\right)_{2}(1,2-\right.$ pda)(1,4-pda) 2 (16), the last two containing also dimethylammonium cations. These four complexes have the same 2:3 uranyl/ligand stoichiometry as 7-12, with complex $\mathbf{1 6}$ containing a mixture of the 1,2 and 1,4 isomers in the same ratio as complex 11 (no complex with 1,2$\mathrm{pda}^{2-}$ ligands alone and phosphonium cations could be crystallized). In these four cases also, all uranium atoms are tris-chelated and thus 3-c nodes, and all ligands are bis-chelating links, and the 1D coordination polymers formed, parallel to [1ī1], [100], [32ī], and [001], respectively, display geometries previously encountered, since dinuclear ring-containing daisychains are formed in 13, 15 and 16, and a ladder-like chain in 14 (Figures 8 and 9). The 1,3-pda ${ }^{2-}$ ligands in $\mathbf{1 3}$ have the same conformation as in $\mathbf{9}$, i.e. cis in the dinuclear rings, and trans for the ring-connecting, disordered ligand, which results in the chains being linear. The unique $\mathrm{PPh}_{3} \mathrm{Me}^{+}$cation has its methyl group pointing toward the ring, each ring being thus associated with two cations, one on each side, related by inversion. The interaction between the two moieties is essentially electrostatic, and only three $\mathrm{CH} \cdots \mathrm{O}$ hydrogen bonds can be discerned, involving one methyl and two aromatic protons of the counterion, and oxido or 


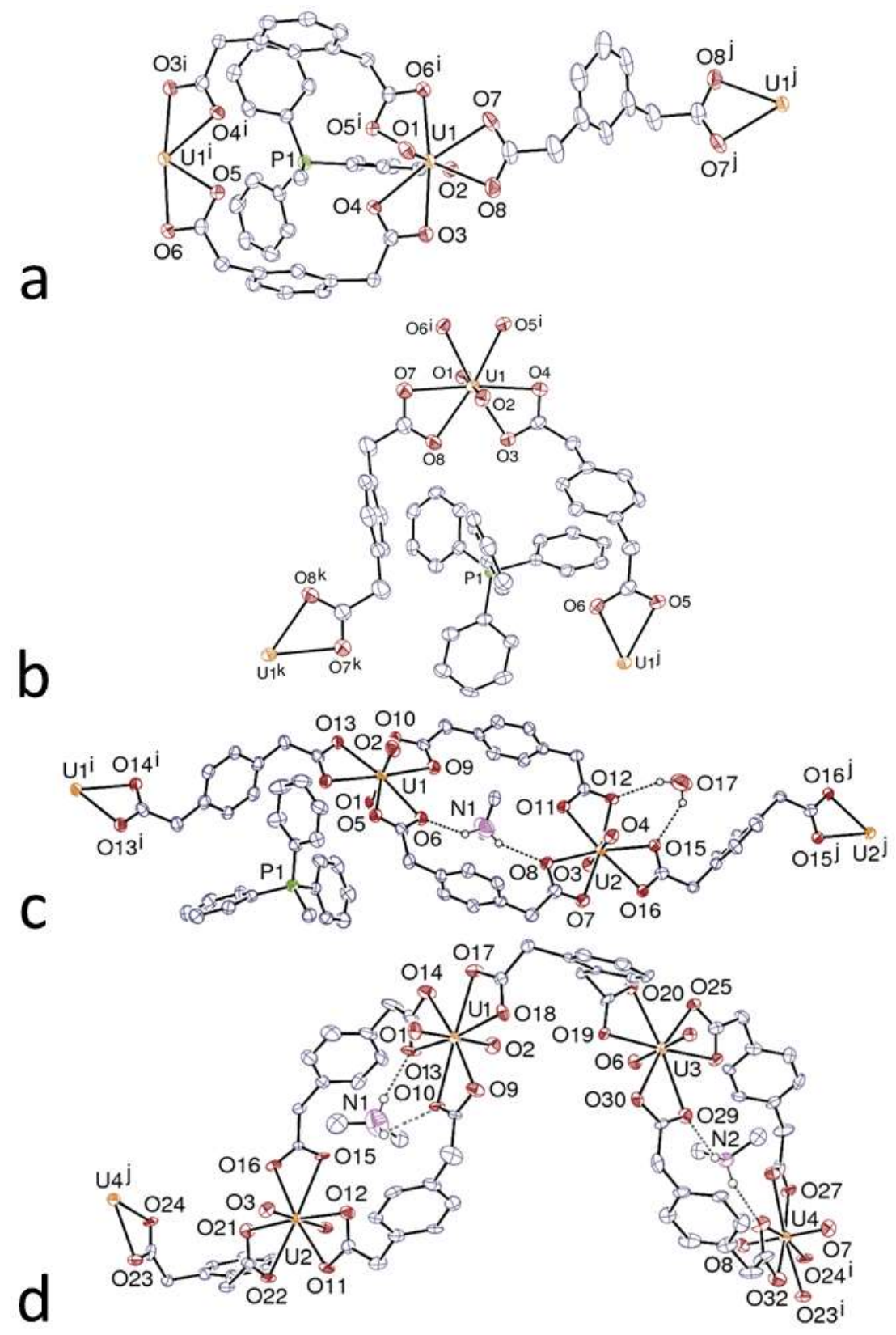

Figure 8. Views of compounds 13 (a), 14 (b), 15 (c), and 16 (d) with phosphonium cation in 16 and carbon-bound hydrogen atoms omitted. Hydrogen bonds are shown as dashed lines. Only one position of the disordered aromatic ring in $\mathbf{1 3}$ is shown. Symmetry codes: $\mathbf{1 3} \mathrm{i}=1-x, 1-y, 1-z ; \mathrm{j}=-x, 2-y,-z ; \mathbf{1 4} \mathrm{i}=x+1, y, z ; \mathrm{j}=x-1, y, z ; \mathrm{k}$ $=1-x, 1-y, 1-z ; \mathbf{1 5} \mathrm{i}=-x,-y, 2-z ; \mathrm{j}=3-x, 2-y, 1-z ; \mathbf{1 6} \mathrm{i}=x, y, z+1 ; \mathrm{j}=x, y, z-1$.

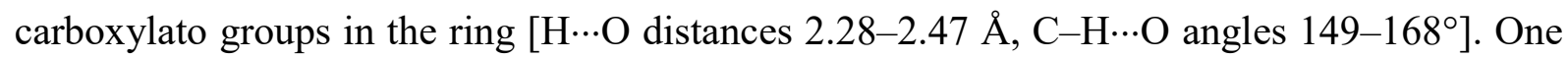
$\pi$-stacking interaction may also unite one phosphonium ring with the disordered ligand in trans

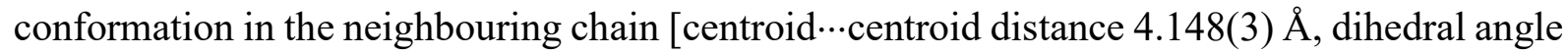




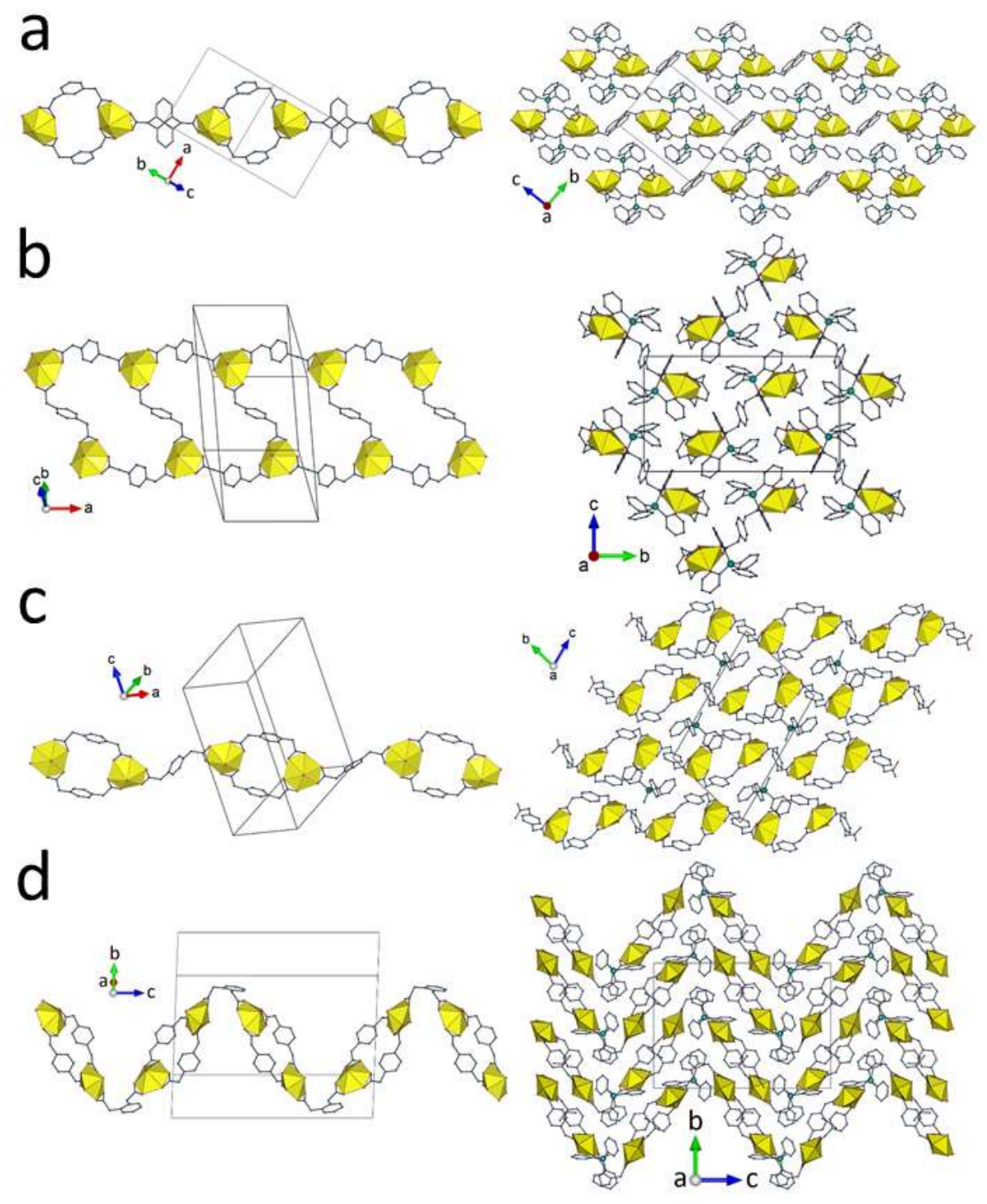

Figure 9. Views of the 1D polymer (left) and the packing (right) in compounds 13 (a), 14 (b), 15 (c), and 16 (d).

$\left.31.2(2)^{\circ}\right]$. The two independent 1,4-pda ${ }^{2-}$ ligands in $\mathbf{1 4}$ (one of them centrosymmetric) are in the trans conformation, and as a result no dinuclear ring is formed, the 1D polymer being analogous to that in the 1,2-pda ${ }^{2-}$ complexes 7 and $\mathbf{8}$. Two $\mathrm{PPh}_{4}{ }^{+}$counterions are associated with each tetranuclear cell, with one aromatic ring of each included in it. Two $\pi$-stacking interactions may exist between the included aromatic ring and that of the centrosymmetric, central ligand (involved in two such interactions), and between another aromatic ring of the

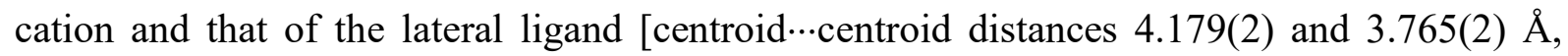
dihedral angles 17.1(2) and 13.04(19) ${ }^{\circ}$, respectively]. Additionally, the counterions associated 
with neighbouring chains form dimers through colinear sextuple phenyl embraces, with a P...P distance of 5.929(2) $\AA$ typical of such arrangements, ${ }^{30}$ and the packing is quite compact (KPI 0.70). Coexistence of cis and trans 1,4-pda ${ }^{2-}$ ligands in complex 15 results in the formation of a daisychain-type 1D polymer similar to that in 9 and 13. The interesting point here is that $\mathrm{H}_{2} \mathrm{NMe}_{2}{ }^{+}$cations displace $\mathrm{PPh}_{3} \mathrm{Me}^{+}$cations from the dinuclear rings, with which they are associated through hydrogen bonding to carboxylato groups [N‥O distances $2.867(6)$ and 3.053(6) $\AA, \mathrm{N}-\mathrm{H} \cdots \mathrm{O}$ angles 142 and $\left.148^{\circ}\right]$. The two ligands in the dinuclear rings may possibly be involved in parallel displaced $\pi$-stacking interactions with their counterparts in two neighbouring chains [centroid $\cdots$ centroid distances 4.244(2) and 4.394(2) $\AA$, dihedral angles $0^{\circ}$ ]. With no P...P distance shorter than $9.4 \AA$, the $\mathrm{PPh}_{3} \mathrm{Me}^{+}$cations do not form any phenyl embraces. As usual, an intricate network of $\mathrm{OH}($ water) $\cdots \mathrm{O}, \mathrm{CH} \cdots \mathrm{O}$ and $\mathrm{CH} \cdots \pi$ interactions is present in the packing (KPI 0.67). Finally, the coexistence of cis 1,2-pda ${ }^{2-}$ (with however one arm closer to the aromatic plane than the other) and cis $1,4-\mathrm{pda}^{2-}$ ligands in $\mathbf{1 6}$ produces a daisychain-like zigzag polymer similar to that in complex 11. Here also, the two independent $\mathrm{H}_{2} \mathrm{NMe}_{2}{ }^{+}$cations are included in the rings and each forms two hydrogen bonds with carboxylate oxygen atoms bound to the same uranium atom or to the two uranium atoms in the ring $[\mathrm{N} \cdots \mathrm{O}$ distances $2.76(2)-2.985(18) \AA, \mathrm{N}-\mathrm{H} \cdots \mathrm{O}$ angles $\left.111-164^{\circ}\right]$. The aromatic rings of the 1,2-pda ${ }^{2-}$ ligands may have $\pi$-stacking interactions with rings of the $\mathrm{PPh}_{3} \mathrm{Me}^{+}$counterions

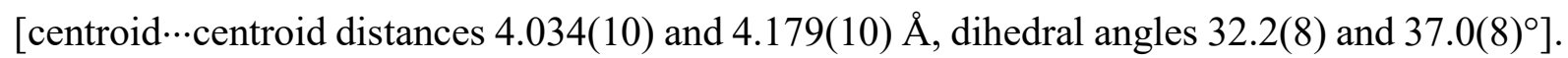
The P...P separations are larger than 9.6 ̊, and no phenyl embrace interaction is apparent. As usual, the packing (KPI 0.68) displays numerous $\mathrm{CH} \cdots \mathrm{O}$ and $\mathrm{CH} \cdots \pi$ interactions.

As previously noted, ${ }^{10}$ the preferred coordination mode of all three $\mathrm{pda}^{2-}$ isomers is the bis- $\kappa^{2} O, O^{\prime}$-chelating one, found here as the sole coordination mode in complexes $\mathbf{7 - 1 6}$, in one out of two ligands in $\mathbf{6}$, and combined with bridging (bis- $\left.\mu_{2}-\kappa^{1} O: \kappa^{2} O, O^{\prime}\right)$ in $\mathbf{1}$. The second most 
frequent mode is that in which one carboxylate is chelating and the other bridging $\left(\kappa^{2} O, O^{\prime} / \mu_{2}-\right.$ $\kappa^{1} O: \kappa^{1} O^{\prime}$ ), found in 3-5. Only in complexes 2 and $\mathbf{6}$ are different modes observed, $\mu_{2-}$ $\kappa^{1} O: \kappa^{2} O, O^{\prime} / \mu_{2}-\kappa^{1} O: \kappa^{1} O^{\prime}$ and bis- $\mu_{2}-\kappa^{1} O: \kappa^{1} O^{\prime}$, respectively (Scheme 1$)$. Since even in the case

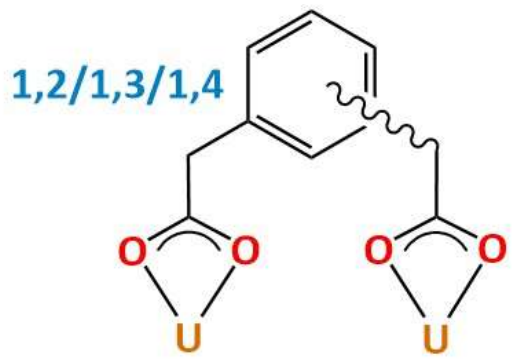

6-16

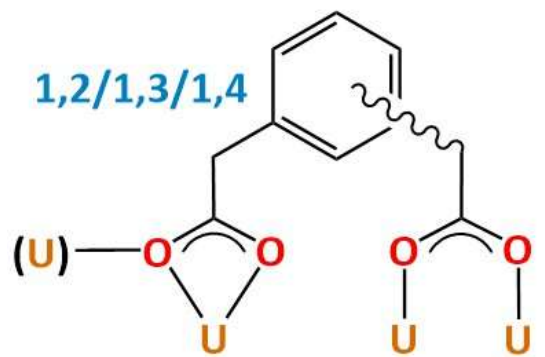

2-5

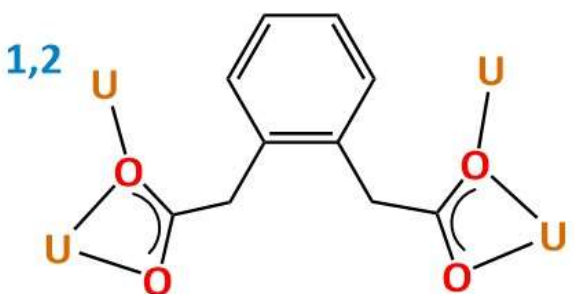

1

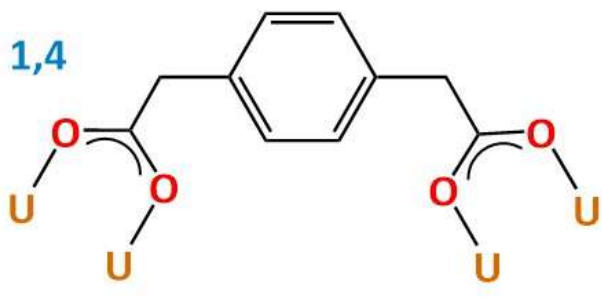

6

Scheme 1 Coordination modes of the three isomers of $\mathrm{pda}^{2-}$ in complexes $\mathbf{1}-\mathbf{1 6}$. The $\mathrm{U}$ in parenthesis corresponds to the additional bonding in complex 2.

of $1,2-\mathrm{pda}^{2-}$ the smallest chelate ring that could be formed if both carboxylates were to bind to one metal ion would be 9-membered, a situation which is unknown in uranyl carboxylate systems except for conformationally restricted ligands, ${ }^{31}$ it is unsurprising that such a form of chelation is not observed in any of the present complexes. From a topological viewpoint, these ligands are thus most often simple links, with less frequent occurrences as 3- or 4-c nodes. This accounts for monoperiodic coordination polymers being formed in most cases, with only a small proportion of diperiodic networks and no example of a triperiodic framework, either in this or previous studies. ${ }^{9,10}$ The variable conformation of the ligands introduces however some differences. Due to the proximity of the substituents, $1,2-\mathrm{pda}^{2-}$ is generally in the trans, pseudo$C_{2}$ conformation, with in some cases one arm straddling the aromatic plane and only one 
instance of a cis conformation in the present series (16, other examples have however been reported $^{10}$ ). The 1,3 and 1,4 isomers show lesser distinction between cis and trans conformers, resulting in the frequent occurrence of $\left(\mathrm{UO}_{2}\right)_{2}(\mathrm{pda})_{2}$ dinuclear rings involving the cis form, which are assembled into daisychain-like polymers, whereas the 1,2 isomer forms preferentially ladder-like chains. The rotational freedom of all $\mathrm{pda}^{2-}$ species provides significant flexibility in regard to their donor atom arrays, partly reflected in the formation of some very similar polymer structures by different isomers.

A major influence on the coordination mode adopted and the periodicity of the species formed comes from the additional coligands and counterions. While the neutral and homoleptic complexes $\mathbf{1}$ and $\mathbf{2}$ crystallize as diperiodic assemblies in which both metal and ligand are 4-c nodes, introduction of a coordinating, monodentate solvent molecule results either in reduction of the periodicity in $\mathbf{4}$, or in the formation of diperiodic assemblies in which both metal and ligand are 3-c nodes ( 3 and $\mathbf{5}$ ) or the metal is a 3-c node and the ligand a 4-c node or a simple link (6). It is notable that the majority of diperiodic arrangements have been found within this group of neutral complexes, with only one example in an anionic complex involving the guanidinium counterion (12). Dimethylammonium and phosphonium cations, either alone or together, promote the formation of monoperiodic polymers with ladder-like or daisychain-like geometry. The dinuclear rings present in the latter are closely associated either with methyl groups of $\mathrm{PPh}_{3} \mathrm{Me}^{+}$cations in $\mathbf{1 3}$ or with hydrogen bonded ammonium cations in the other cases, so that this frequent arrangement is not selectively promoted by one particular cation.

In combination with our previous work, ${ }^{9,10}$ the present examples bring to 40 the number of known structures of uranyl ion complexes of the isomeric phenylenediacetates, 16 of these involving the 1,2 isomer, 11 the 1,3 and 16 the 1,4 (the total here exceeding 40 because of 3 structures involving mixed, 1,2- and 1,4-pda ${ }^{2-}$ ligands). Within the 40, 10 involve uranyl ion as the sole cation and 30 involve uranyl ion and at least one other cation, either a metal ion, an 
ammonium ion or a phosphonium ion. Thus, there is a substantial basis for an analysis of the factors which affect the limited conformational flexibility of $\mathrm{pda}^{2-}$ ligands and thereby the form of their complexes. Given that the flexibility of $\mathrm{pda}^{2-}$ ligands is dependent upon rotation about two bonds, (Ar)C-C and $\mathrm{C}-\mathrm{CO}_{2}^{-}$, with the former providing a means of displacing the carboxylate units out of the plane of the phenyl ring and changing their distance of separation, consideration that this flexibility could be used to minimise repulsion between like charges leads to the conclusion that the most favoured conformation for all three isomeric ligands would be the trans form, while a cis conformation would be unfavourable. Since the barrier to rotation about a simple $\mathrm{C}-\mathrm{C}$ single bond is typically $\sim 12 \mathrm{~kJ} \mathrm{~mol}^{-1},{ }^{32}$ and is an energy spanned by that of hydrogen bonds, which range from $\sim 12 \mathrm{~kJ} \mathrm{~mol}^{-1}$ for a weak interaction such as $\mathrm{CH} \cdots \mathrm{O},{ }^{27}$ to $>100 \mathrm{~kJ} \mathrm{~mol}^{-1}$ for a strong interaction such as $\mathrm{OH} \cdots \mathrm{O},{ }^{33,34}$ it might be anticipated that any deviation from a trans form might be associated with such interactions. This, no doubt, is an oversimplified argument, given, for example, that the carboxylate group is not a sphere of negative charge and its coordination would drastically modify repulsion effects, but has proved to be a useful starting point for analysis of all 40 structures referred to above.

The $\mathrm{pda}^{2-}$ ligand conformations found in the 40 structures are depicted in Figure S1 (Supplementary Information). In many instances, the structures contain inequivalent ligand sites associated with very slight as well as major conformational differences but as a broad generalisation it can be said that nearly all conformers have essentially either a cis or trans form, examples in the present work having been given above. Slightly more than half the structures are of complexes which do not contain strong hydrogen bond ( $\mathrm{NH}$ and/or $\mathrm{OH})$ donors and these provide a useful starting point for analysis. Taking first the complexes of 1,2-pda ${ }^{2-}$, the ligand where substituent repulsions would be expected to be greatest, of the six complexes where potentially strong hydrogen bond donors are not present, in four the ligand conformations are clearly trans, even though they differ significantly, as reflected in ${ }^{-} \mathrm{O}_{2} \mathrm{C} \cdots \mathrm{CO}_{2}^{-}$distances 
which vary from a maximum of $4.478(5) \AA$ in 1 to a minimum of $3.838(7) \AA$ in $\left[\mathrm{UO}_{2}(1,2-\right.$ pda)(bipy)] $\cdot \mathrm{CH}_{3} \mathrm{CN}^{10}$ In the two other complexes, where the ligand conformation is best described as intermediate between cis and trans, one carboxylate-C being close to lying in the phenyl plane and thus presumably being involved in some degree of repulsion with phenyl hydrogen atoms, the ${ }^{-} \mathrm{O}_{2} \mathrm{C} \cdots \mathrm{CO}_{2}{ }^{-}$distances are actually longer at 5.435(4) $\AA$ in $\mathbf{3}$ and 4.796(8) $\AA$ in $\left[\mathrm{UO}_{2}(1,2-\mathrm{pda})(\mathrm{phen})\right] .{ }^{10}$ One distinguishing feature of these two structures is the nature of $\mathrm{CH} \cdots \mathrm{O}$ interactions (identified from calculation of the Hirshfeld surfaces) between ligands, the former involving pairwise DMPU...DMPU interactions which must not only distort the uranyl ion coordination sphere to some extent but which place $\mathrm{N}-\mathrm{CH}_{3}$ groups in close proximity to the centroids of the 1,2-pda ${ }^{2-}$ phenyl rings (although the HS shows no interaction beyond dispersion). The structure of the latter $\left(\left[\mathrm{UO}_{2}(1,2-\mathrm{pda})(\mathrm{phen})\right]\right)$ provides a contrast with that of the very similar complex $\left[\mathrm{UO}_{2}(1,2-\mathrm{pda})(\right.$ bipy) $] \cdot \mathrm{CH}_{3} \mathrm{CN}$ (where, as noted above, ${ }^{-} \mathrm{O}_{2} \mathrm{C} \cdots \mathrm{CO}_{2}{ }^{-}$is only $3.838(7) \AA$ ) in that within the polymer chain present there are $\mathrm{CH} \cdots \mathrm{O}$ interactions $(\mathrm{O} \cdots \mathrm{H}$ $2.62 \AA$ ) which link the phen and 1,2-pda ${ }^{2-}$ ligands but which are absent in the bipy analogue (Figure S2). In the seven structures of complexes of 1,2-pda ${ }^{2-}$ alone where strong hydrogen bond donors are present, conformations describable as trans are again dominant, being the only form found in 7, 8, 12, and $\left[\mathrm{Zn}(\text { phen })_{3}\right]\left[\left(\mathrm{UO}_{2}\right)_{2}(1,2-\mathrm{pda})_{3}\right] \cdot 7 \mathrm{H}_{2} \mathrm{O}^{9}$ but accompanied by an intermediate form, similar to that described above, in $\left[\mathrm{H}_{2}-2.2 .2\right]\left[\left(\mathrm{UO}_{2}\right)_{2}(1,2-\mathrm{pda})_{3}\right] \cdot \mathrm{CH}_{3} \mathrm{CN}^{10}$ and $\left[\mathrm{UO}_{2}(1,2-\mathrm{pda})_{2} \mathrm{Zn}(\text { phen })_{2}\right] \cdot 2 \mathrm{H}_{2} \mathrm{O} .{ }^{9}$ As the diprotonated cryptand [2.2.2] adopts an "in-in" conformation, it is not capable of acting as a strong hydrogen bond donor towards the uranyl polymer and the complex could thus be included in the first group above, consistent with the fact that nearly all cation $\cdots$ anion interactions beyond dispersion are of the $\mathrm{CH} \cdots \mathrm{O}$ type. Ligand 1, which has a trans conformation, has only one such interaction with the cryptand, whereas ligand 2 has two plus one $\mathrm{C} \cdots \mathrm{HC}$ and ligand 3 has two as a result of bridging two cryptand units, so that the intermediate conformations of these two ligands may reflect the different 
numbers of interactions (Figure S3). Only in $\left[\mathrm{NH}_{4}\right]_{6}\left[\mathrm{Ni}\left(\mathrm{H}_{2} \mathrm{O}\right)_{6}\right]_{2}\left[\left(\mathrm{UO}_{2}\right)_{4}(1,2-\right.$ pda $\left.)_{6}\right]_{2}\left[\left(\mathrm{UO}_{2}\right)_{4}(1,2-\mathrm{pda})_{5}\left(\mathrm{H}_{2} \mathrm{O}\right)_{4}\right]^{10}$ are real examples of what could be termed cis conformations found, here in equal number with trans.

In the two complexes $\mathbf{7}$ and $\mathbf{8}$, what is notable is that the same polymer, with ligands in a trans conformation, is present despite rather different hydrogen bonding arrays involving the cation and water binding to carboxylate oxygen atoms independently in the case of the monohydrate or jointly, in the case of the trihydrate. The extensive hydrogen bonding must have an influence on the structure but in neither case does it involve bridging of carboxylate oxygen atoms of one particular ligand unit, bridging which could have some influence on the ligand conformation. However, in the structure of 12, where each of the four inequivalent guanidinium cations is involved in six hydrogen bonds, largely to carboxylate groups, there is one case of such bridging and it does not appear to have an influence on the ligand conformation, as this ligand has essentially a trans form (Figure S4). This could, of course, simply mean that the trans conformation is suited to bridging by a properly oriented guanidinium ion amino group, a conclusion supported by the fact that in $\left[\mathrm{Zn}(\text { phen })_{3}\right]\left[\left(\mathrm{UO}_{2}\right)_{2}(1,2-\mathrm{pda})_{3}\right] \cdot 7 \mathrm{H}_{2} \mathrm{O},{ }^{9}$ where again only the trans conformation is found, there is bridging not by a single water molecule but by a group of three able to span the relatively distant carboxylate sites.

The structure of the complex $\left[\mathrm{UO}_{2}(1,2-\mathrm{pda})_{2} \mathrm{Zn}(\mathrm{phen})_{2}\right] \cdot 2 \mathrm{H}_{2} \mathrm{O}^{9}$ shows that the 1,2-pda ${ }^{2-}$ ligand which bridges uranium centres has a conformation intermediate between cis and trans and that carboxylate oxygen atoms of this ligand are bridged by a pair of water molecules, one of these water molecules also bridging the coordination spheres of the $\mathrm{U}^{\mathrm{VI}}$ and $\mathrm{Zn}^{\mathrm{II}}$ centres linked by a trans-form ligand. What is thus taken to perturb the conformation of the first ligand is its $\mathrm{CH} \cdots \pi$ interaction with a phen ligand on $\mathrm{Zn}^{\mathrm{II}}$ in an adjacent polymer chain. That an $\mathrm{NH}_{2}$ unit is ideally suited to hydrogen bond bridging of adjacent carboxylate oxygen atoms of 
different $\kappa^{2} O, O^{\prime}$ chelate ligands on hexagonal-bipyramidal $\mathrm{U}^{\mathrm{VI}}$ is indicated by the double interactions of this sort of the three inequivalent ammonium ions in the structure of $\left[\mathrm{NH}_{4}\right]_{6}\left[\mathrm{Ni}\left(\mathrm{H}_{2} \mathrm{O}\right)_{6}\right]_{2}\left[\left(\mathrm{UO}_{2}\right)_{4}(1,2-\mathrm{pda})_{6}\right]_{2}\left[\left(\mathrm{UO}_{2}\right)_{4}(1,2-\mathrm{pda})_{5}\left(\mathrm{H}_{2} \mathrm{O}\right)_{4}\right] .{ }^{10}$ Since it is associated with complex units in which the ligands have both cis and trans conformations, at first sight it does not appear to be a factor directly influencing the conformation. However, there are six ligands with a cis conformation and these form three pairs which are linked into 18-membered rings by two uranyl ions, the rings having a cup-like shape surrounding an ammonium ion poised above the centroids of the two facing phenyl rings (Figure S5). While the centroid $\cdots \mathrm{N}$ distances are near $3.8 \AA$ and thus rather long for any strong interaction, it appears that $\mathrm{N}^{+} \ldots \pi$ interactions could be the reason for the adoption of the cis conformation of the ligands. As a small cation, ammonium ion may have a unique role in this regard.

The greater separation of the substituents in $1,3-\mathrm{pda}^{2-}$ relative to that in $1,2-\mathrm{pda}^{2-}$ should mean that any effects of substituent repulsion would be diminished, even if a trans conformation would be preferred on this basis alone. In fact, although in the majority of known structures, 1,3-pda ${ }^{2-}$ adopts conformations better described as trans rather than cis, there are several instances, found in $\mathbf{9}, \mathbf{1 3},\left[\mathrm{Zn}(\text { bipy })_{3}\right]\left[\left(\mathrm{UO}_{2}\right)_{2}(1,3-\mathrm{pda})_{3}\right],{ }^{9}$ and $\left[\mathrm{UO}_{2} \mathrm{~Pb}(1,3-\right.$ pda $)_{2}$ (phen) $],{ }^{10}$ where at least one of the inequivalent ligand units in the structure has a cis conformation. In all four, these cis ligands are involved as pairs in the formation of di- or tetrauranocyclic entities, 18-membered (diuranyl) in all cases except in $\left[\mathrm{Zn}(\text { bipy })_{3}\right]\left[\left(\mathrm{UO}_{2}\right)_{2}(1,3-\right.$ pda) 3 , where they are 36-membered (tetrauranyl), which define cavities in the structure. There is thus a resemblence to the cup-like unit described above in the structure of $\left[\mathrm{NH}_{4}\right]_{6}\left[\mathrm{Ni}\left(\mathrm{H}_{2} \mathrm{O}\right)_{6}\right]_{2}\left[\left(\mathrm{UO}_{2}\right)_{4}(1,2-\mathrm{pda})_{6}\right]_{2}\left[\left(\mathrm{UO}_{2}\right)_{4}(1,2-\mathrm{pda})_{5}\left(\mathrm{H}_{2} \mathrm{O}\right)_{4}\right]$. In 9, the $\mathrm{NH}_{2}$ component of the cation behaves like that in ammonium ion by bridging carboxylate oxygen atoms of separate ligand units through hydrogen bonding but the cation is also involved in $\mathrm{CH} \cdots \mathrm{O}$ interactions of the methyl groups, making it overall a linking unit of rather different dimensions 
to $\mathrm{NH}_{4}{ }^{+}$. All its interactions in $\mathbf{9}$ nonetheless have a similar consequence to ammonium in $\left[\mathrm{NH}_{4}\right]_{6}\left[\mathrm{Ni}\left(\mathrm{H}_{2} \mathrm{O}\right)_{6}\right]_{2}\left[\left(\mathrm{UO}_{2}\right)_{4}(1,2-\mathrm{pda})_{6}\right]_{2}\left[\left(\mathrm{UO}_{2}\right)_{4}(1,2-\mathrm{pda})_{5}\left(\mathrm{H}_{2} \mathrm{O}\right)_{4}\right]$ in that they place two cations within the cavity defined by the diuranocycle, with methyl groups projecting towards the aromatic rings. This is a situation somewhat reminescent of aspects of calix[4]arene chemistry, where methyl groups of simple species such as tetramethylammonium can be found within the cavity lined by aromatic groups. ${ }^{35}$ A similar substructure is found in $\mathbf{1 3}$, where the $\mathrm{P}^{+}-\mathrm{CH}_{3}$ groups of two cations protrude into the 18 -membered ring cavity, and in $\left[\mathrm{UO}_{2} \mathrm{~Pb}(1,3-\right.$ pda) 2 (phen)], where phen ligands on $\mathrm{Pb}^{\mathrm{II}}$ partly occupy the cavity, drawn in by $\mathrm{CH} \cdots \mathrm{O}$ (uranyl) interactions. In $\left[\mathrm{Zn}(\text { bipy })_{3}\right]\left[\left(\mathrm{UO}_{2}\right)_{2}(1,3-\mathrm{pda})_{3}\right]$, the larger tetrauranocyclic rings are linked in an undulating manner possible because of the adoption of the cis conformation of two opposite ligand units and which enables the $\left[\mathrm{Zn}(\text { bipy })_{3}\right]^{2+}$ cations to insert into the undulations in such a way as to give a stacked array of four trans ligands in adjacent rings with bound phen. Thus, as might be expected when there is no strong preference for one conformation over another, weak interactions appear sufficient to cause displacement from one to the other.

Extension of this argument would indicate that minor interactions could equally well influence the conformation adopted by $1,4-\mathrm{pda}^{2-}$. Although in the known structures of uranyl ion complexes the trans conformer can be said to be predominant, if in various quite different approximations to the extreme form with $\mathrm{C}-\mathrm{CO}_{2}{ }^{-}$bonds perpendicular to the phenyl plane, there are several instances of cis conformations, found in the structures of the complexes $\mathbf{1 0}$, 15, $\left[\mathrm{UO}_{2}(1,4-\mathrm{pda})_{2} \mathrm{Mn}(\text { bipy })_{2}\right] \cdot \mathrm{H}_{2} \mathrm{O},\left[\mathrm{M}(\text { bipy })_{3}\right]\left[\left(\mathrm{UO}_{2}\right)_{2}(1,4-\mathrm{pda})_{3}\right](\mathrm{M}=\mathrm{Co}, \mathrm{Ni}, \mathrm{Ru})$, and $\left[\mathrm{Ni}(\text { phen })_{3}\right]\left[\left(\mathrm{UO}_{2}\right)_{2}(1,4-\mathrm{pda})_{3}\right] \cdot \mathrm{H}_{2} \mathrm{O} .{ }^{9}$ In the case of 10, where all three inequivalent ligand units have a cis conformation, disorder renders precise analysis of the cation interactions difficult, but whether as an opposed pair in an 18-membered diuranocyclic unit or as a bridging ligand between these metallacycles, the ligands are all closely associated with a cation held by $\mathrm{NH} \cdots \mathrm{O}$ and $\mathrm{CH} \cdots \mathrm{O}$ bonding above the aromatic ring. In $\mathbf{1 5}$, where ligands in the cis conformation are 
found as pairs in 18-membered diuranocycles and those in the trans conformation serve as links between these rings, there is a clear distinction of cation roles in that the $\mathrm{H}_{2} \mathrm{NMe}_{2}{ }^{+}$cations lie within the macrocycles, here with the $\mathrm{N}^{+}$centre midway between the centroids of the two phenyl planes, while the cations make only rather remote approaches to both sides of the bridging ligand phenyl plane. Note that in $\mathbf{1 4}$ a different uranyl polymer containing only trans conformation ligands is present and interactions between the aromatic entities of cations and anions appear to be of the $\mathrm{CH} \cdots \pi$ type only. In $\left[\mathrm{UO}_{2}(1,4-\text { pda })_{2} \mathrm{Mn}(\text { bipy })_{2}\right] \cdot \mathrm{H}_{2} \mathrm{O}$, however, the ligands in a cis conformation again form facing pairs in 18-membered diuranocyclic units and bipy entities from adjacent heterometallic polymer strands to each side are partially inserted between them, indicating that even such a weak interaction can favour the formation of the cup-like rings and their associated cis ligand conformation. What is possibly a more remote mechanism for influencing the ligand conformation, as already seen in the structure of $\left[\mathrm{Zn}(\text { bipy })_{3}\right]\left[\left(\mathrm{UO}_{2}\right)_{2}(1,3-\mathrm{pda})_{3}\right]$, is in evidence in the structures of $\left[\mathrm{M}(\text { bipy })_{3}\right]\left[\left(\mathrm{UO}_{2}\right)_{2}(1,4-\mathrm{pda})_{3}\right]$ $(\mathrm{M}=\mathrm{Co}, \mathrm{Ni}, \mathrm{Ru})$, where cis ligand bridging of uranyl units linked by trans ligands gives 36membered rings which are fused into a corrugated structure where one bipy ligand of $\left[\mathrm{M}(\text { bipy })_{3}\right]^{2+}$ is inserted in a stacked array between four phenyl groups of the trans ligands of two adjacent (fused) tetrauranocycles. Aromatic...aromatic interactions of the same dispersive nature involving all three ligands of $\left[\mathrm{Ni}(\mathrm{phen})_{3}\right]^{2+}$ give rise to a much more complicated array of diperiodic uranyl polymers in the structure of $\left[\mathrm{Ni}(\mathrm{phen})_{3}\right]\left[\left(\mathrm{UO}_{2}\right)_{2}(1,4-\mathrm{pda})_{3}\right] \cdot \mathrm{H}_{2} \mathrm{O}$, where there is insertion of one phen ligand between facing phenyl units of trans ligands as well as partial insertion of two phen ligands into each side of cup-shaped 18-membered diuranocycles involving cis ligands. These interactions serve to link the polymeric sheets together.

The structures of the mixed (1,2- and 1,4-pda $\left.{ }^{2-}\right)$ ligand complexes 11, 16, and $\left.[\mathrm{Zn} \text { (bipy) })_{3}\right]\left[\left(\mathrm{UO}_{2}\right)_{2}(1,2-\mathrm{pda})(1,4-\mathrm{pda})_{2}\right] \cdot \mathrm{H}_{2} \mathrm{O}^{10}$ provide further examples of the complexity involved in interpreting the role of weak interactions as structure determinants but also provide 
indications of the relative strength of different cations in influencing ligand conformations within anionic uranyl ion polymers. As has been noted above in relation to the structure of $\mathbf{9}$, the dimethylammonium cation is not to be considered as just half of an ammonium ion. In the structure of 11, where both ligand isomers have cis conformations (approximately so for the 1,2- $\mathrm{pda}^{2-}$ units) both of the inequivalent cations are intimately associated with the anionic polymer, with the distinction between the two cations being that one is associated with one 1,2-pda ${ }^{2-}$ unit while the other is enclosed between two 1,4-pda ${ }^{2-}$ ligands found in the same 22membered diuranocyclic unit of the polymer. For both, the $\mathrm{NH}_{2}$ components do indeed act as bridges between uranyl centres by hydrogen bonding to carboxylate groups but for the former these groups are from separate 1,2 and 1,4 ligands, whereas in the latter they are from the same 1,4 ligand, thus obviously favouring the cis conformation there. As evident in the HSs, both the cations are involved in additional weak interactions of $\mathrm{CH} \cdots \mathrm{O}$ type involving the methyl groups but in the cation contacting the 1,2 ligand through an $\mathrm{NH} \cdots \mathrm{O}$ bond, these involve just one methyl group, the other being poised above the phenyl group of the ligand in a manner suggestive of a $\mathrm{CH} \cdots \pi$ interaction which may be a factor favouring the ligand's near-cis conformation. For the other cation, it is the $\mathrm{N}^{+}$centre which is located essentially on the line linking the centroids of the two phenyl groups of the enclosing diuranocycle (centroid $\cdots \mathrm{N} \cdots$ centroid angle $172^{\circ}$ ). In $\mathbf{1 6}$, where the same anionic polymer is present, the (two inequivalent) $\mathrm{H}_{2} \mathrm{NMe}_{2}{ }^{+}$cations retain the same intimate contact with the polymer in that they occupy the cavities formed by the $\left(\mathrm{UO}_{2}\right)_{2}(1,4-\mathrm{pda})_{2}$ rings, while the $\mathrm{PPh}_{3} \mathrm{Me}^{+}$cations, perhaps unsurprisingly given their large size, are not simply located close to the 1,2 ligands but make $\mathrm{CH} \cdots \mathrm{O}$ contacts to both 1,2 and 1,4 species which do not result in bridging of the oxygen centres of one ligand. Thus, it appears that $\mathrm{H}_{2} \mathrm{NMe}_{2}{ }^{+}$must be a more effective bridging unit for $\mathrm{pda}^{2-}$ ligands than $\mathrm{PPh}_{3} \mathrm{Me}^{+}$and therefore a stronger influence upon the ligand conformation. However, it must be noted that inspection of the HSs of the inequivalent cations 
indicates that their interactions beyond dispersion with the enclosing macrocycle are quite different, a somewhat unexpected situation being that of the cation containing N1, which bridges the carboxylate units of one ligand through $\mathrm{NH} \cdots \mathrm{O}$ and $\mathrm{CH} \cdots \mathrm{O}$ interactions rather than two $\mathrm{NH} \cdots \mathrm{O}$; one of the $\mathrm{NH}$ hydrogen atoms also contacts an aromatic carbon atom. Such variations indicate that while these interactions may stabilise a given conformation relative to another, they are probably not dominant in determining that conformation. Nonetheless, a more significant change in the countercation, as seen in the structure of $\left[\mathrm{Zn}(\text { bipy })_{3}\right]\left[\left(\mathrm{UO}_{2}\right)_{2}(1,2-\right.$ pda)(1,4-pda) 2$] \cdot \mathrm{H}_{2} \mathrm{O}$, is associated with the formation of a diperiodic rather than a monoperiodic uranyl polymer, the adoption of a trans form for the 1,2-pda ${ }^{2-}$ ligands and of both cis and trans forms for the 1,4-pda ${ }^{2-}$ ligands. Contacts between the cations and the 1,2$\mathrm{pda}^{2-}$ ligands are quite limited and involve single $\mathrm{CH} \cdots \mathrm{O}$ interactions of separate cations with the two oxygen atoms of one carboxylate group, which may explain why the presumably preferred trans conformation is seen. The cis 1,4-pda ${ }^{2-}$ ligands are, as in the other two mixed ligand complexes, present in 18-membered diuranocyclic units and thus define cavities into which bipy ligands project from each side. These intrusions are associated with $\mathrm{CH} \cdots \mathrm{O}$ interactions involving carboxylate and uranyl for each bipy spanning the cavity, and there are no apparent interactions beyond dispersion between the bipy and phenyl moieties, though they do lie in close-to-parallel planes. The trans 1,2-pda ${ }^{2-}$ ligands are involved in a corrugated substructure rather like that seen in the structures of $\left[\mathrm{Zn}(\text { bipy })_{3}\right]\left[\left(\mathrm{UO}_{2}\right)_{2}(1,3-\mathrm{pda})_{3}\right]$ and $\left[\mathrm{M}(\text { bipy })_{3}\right]\left[\left(\mathrm{UO}_{2}\right)_{2}(1,4-\mathrm{pda})_{3}\right](\mathrm{M}=\mathrm{Co}, \mathrm{Ni}, \mathrm{Ru})$, and which again involves insertion of a bipy ligand between pairs of nearly parallel phenyl groups. The only apparent interaction beyond dispersion in the stack here is a single $\mathrm{CH} \cdots \mathrm{O}$ contact to carboxylate at the base of the corrugation. 
Luminescence Properties. Emission spectra under excitation at $420 \mathrm{~nm}$ were recorded in the solid state for all complexes except $\mathbf{9}$ and 16, for which the quantity available was insufficient, and they are represented in Figure 10. In the absence of transition metal cations which often induce quenching of uranyl emission, all spectra display the usual series of wellresolved peaks associated with the vibronic progression corresponding to the $S_{11} \rightarrow S_{00}$ and $S_{10}$ $\rightarrow S_{0 v}(v=0-4)$ electronic transitions. ${ }^{36}$ The spectra of complexes 2-6, in which the uranyl

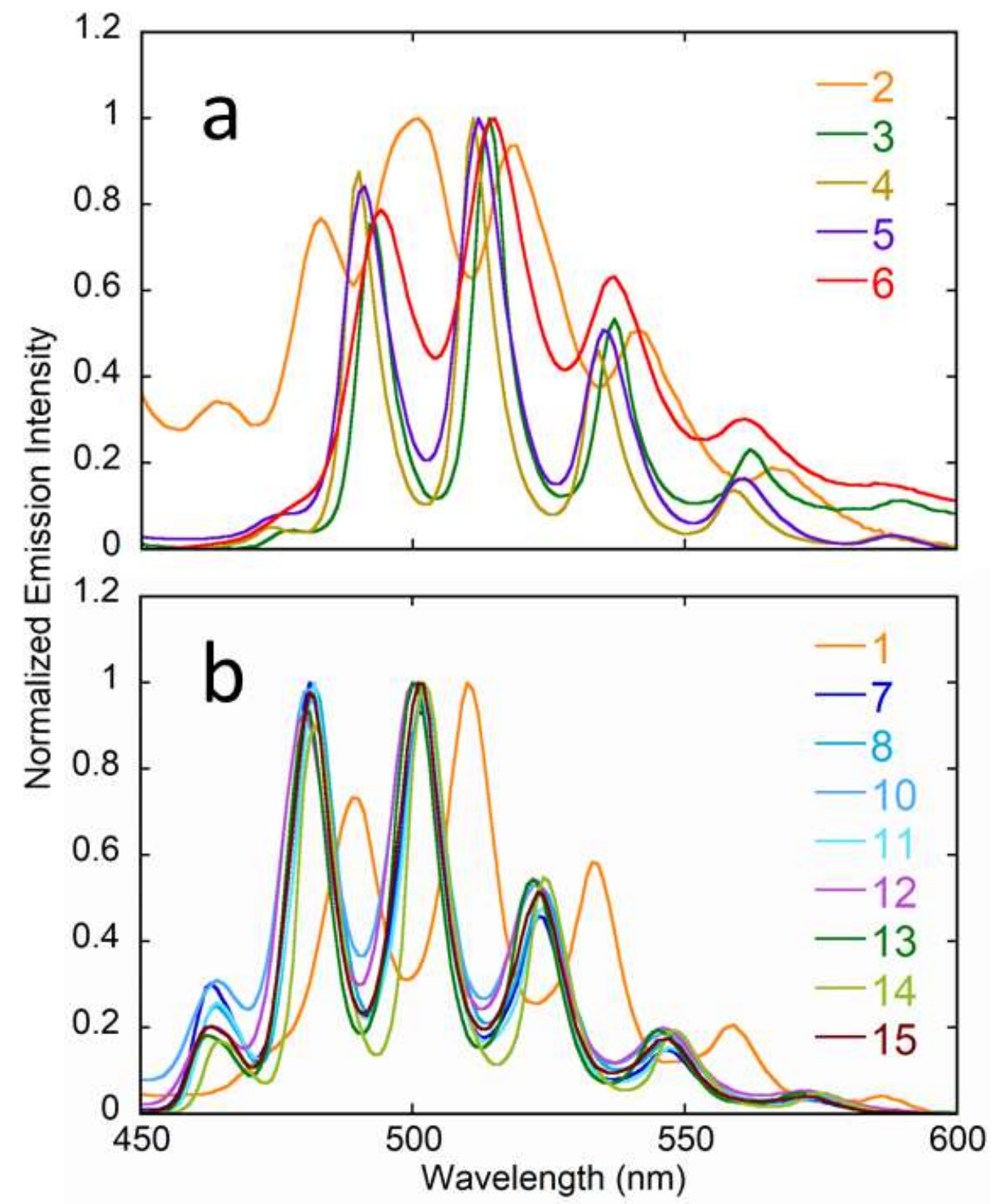

Figure 10. Normalized emission spectra for the complexes with $\mathrm{O}_{5}(\mathrm{a})$ or $\mathrm{O}_{6}$ (b) equatorial environments, recorded in the solid state at room temperature under excitation at a wavelength of $420 \mathrm{~nm}$. 
cation has five equatorial oxygen donors $\left(\mathrm{O}_{5}\right)$, are shown in Figure 10a, and those of complexes 1 and 7, 8, and 10-15, in which there are six equatorial donors $\left(\mathrm{O}_{6}\right)$ are shown in Figure $10 \mathrm{~b}$. The spectra of complexes 3-6, in which the uranyl cation has the same environment of four carboxylate oxygen atoms (two of them in a chelating group) and one oxygen from NMP or DMPU, have maxima positions for the four $S_{10} \rightarrow S_{0 v}(v=0-4)$ peaks located at 490-494, 511$515,534-537$, and 559-562 nm, 6 being the most, and 4 the less red-shifted. These values are in agreement with those generally found for uranyl carboxylate complexes with $\mathrm{O}_{5}$ environments, although at the lower end of the usual range, ${ }^{37}$ but the maxima for complex 2 are distinctly blue-shifted, at $483,501,518$, and $542 \mathrm{~nm}$. The uranyl cation is tris-chelated in all complexes with $\mathrm{O}_{6}$ environment, the geometry being thus pseudo-trigonal, except for $\mathbf{1}$, in which there are two inversion-related chelating groups and two monodentate donors. It appears that all tris-chelated complexes have virtually superimposable emission spectra, with the four $S_{10} \rightarrow S_{0 v}$ peaks located at $480-482,500-502,522-524$, and $545-548 \mathrm{~nm}$, these values being here also in agreement with those generally found for uranyl carboxylate complexes with $\mathrm{O}_{6}$ environments, ${ }^{37}$ while the positions for complex 1 are redshifted by $\sim 9 \mathrm{~nm}$. The usual trend in the evolution of maxima positions with number of equatorial donors is thus found here, except for complexes $\mathbf{1}$ and $\mathbf{2}$, which have the peculiarity in the present series to be the only ones containing close uranyl dimers (2) or chains (1), a difference which, in the absence of any other obvious factor, may be supposed to be the origin of the discrepancy. Solid-state photoluminescence quantum yields (PLQYs) have been measured for several complexes. Those for $\mathbf{1}-\mathbf{3}, \mathbf{5}, \mathbf{6}, \mathbf{1 0}$ and 12 are low $(\sim 1 \%)$, but larger values have been measured for $\mathbf{8}(2.5 \%), \mathbf{1 5}$ (3.3\%), $7(7.2 \%), 14(7.4 \%)$ and particularly $11(14 \%)$. This range of values is similar to those previously found in related complexes, ${ }^{9,10}$ larger values in uranyl carboxylate complexes being uncommon..$^{38,39}$ 


\section{CONCLUSIONS}

We have reported the synthesis, crystal structure and (but for two cases) emission spectrum of 16 uranyl ion complexes with 1,2-, 1,3 or 1,4-phenylenediacetate ligands. As in previous work with these dicarboxylates, monoperiodic coordination polymers are frequently formed, in particular in the anionic complexes with dimethylammonium or phosphonium counterions, but several diperiodic arrangements have been found in neutral complexes and in one anionic species with guanidinium counterions. These networks display diverse topological types, sql, fes, hcb, or 3,4L13, depending on the ligand isomer considered and the additional species present (coordinated solvent, counterion). Among monoperiodic polymers, two geometries are commonly found, ladder-like with the 1,2 isomer, and also in one case with the 1,4 isomer, and daisychain-like with the 1,3 and 1,4 isomers, or mixtures of 1,2 and 1,4 isomers. The conformations adopted by these ligands in the 40 uranyl ion complexes reported here and in previous work are discussed in relation with the weak interactions involving the coligands and/or counterions present. Even the limited conformational flexibility of these ligands is clearly associated with considerable variety in their formation of uranyl ion complexes. For anionic uranyl polymer species, an influence of the counterion is apparent, even if the present works have been limited to cations capable of hydrogen bond donor interactions only (other than where direct coordination of carboxylate to a metal ion occurs). Significantly, different ligand conformations can be associated with different substructures in the coordination polymers, offering promise that in specifically designed ligands where the only flexibility remaining is that of rotation about the $\mathrm{C}-\mathrm{CO}_{2}{ }^{-}$bond a real control of the polymer form could result. That it is possible to have cis, pincer-like conformations with all three isomers (although infrequently with the 1,2 isomer) indicates that these ligands might be used to obtain closed uranyl oligomer complexes, though perhaps only in the presence of a structure-directing, hydrogen bonding species suited to a particular oligomeric form. With two exceptions, the 
emission spectra of the complexes in this series display maxima positions in agreement with those generally observed for uranyl carboxylate complexes with $\mathrm{O}_{5}$ or $\mathrm{O}_{6}$ equatorial environments, with low to moderate photoluminescence quantum yields.

\section{ASSOCIATED CONTENT}

\section{Accession Codes}

CCDC 1966028-1966043 contain the supplementary crystallographic data for this paper. These data can be obtained free of charge via www.ccdc.cam.ac.uk/data_request/cif, or by emailing data_request@ccdc.cam.ac.uk, or by contacting The Cambridge Crystallographic Data Centre, 12 Union Road, Cambridge CB2 1EZ, UK; fax: +44 1223336033.

\section{Supporting Information}

Figures S1-S5. This information is available free of charge via the Internet at http://pubs.acs.org/.

\section{AUTHOR INFORMATION}

\section{Corresponding Authors}

*E-mail: pierre.thuery@,cea.fr. (P.T.)

*E-mail: harrowfield@unistra.fr. (J.H.)

\section{ORCID}

Pierre Thuéry: 0000-0003-1683-570X

Youssef Atoini: 0000-0003-4851-3713

Jack Harrowfield: 0000-0003-4005-740X 


\section{Notes}

The authors declare no competing financial interest.

\section{REFERENCES}

1. Wang, K. X.; Chen, J. S. Extended Structures and Physicochemical Properties of UranylOrganic Compounds. Acc. Chem. Res. 2011, 44, 531-540.

2. Andrews, M. B.; Cahill, C. L. Uranyl Bearing Hybrid Materials: Synthesis, Speciation, and Solid-State Structures. Chem. Rev. 2013, 113, 1121-1136.

3. Loiseau, T.; Mihalcea, I.; Henry, N.; Volkringer, C. The Crystal Chemistry of Uranium Carboxylates. Coord. Chem. Rev. 2014, 266-267, 69-109.

4. Su, J.; Chen, J. S. MOFs of Uranium and the Actinides. Struct. Bond. 2015, 163, 265-296.

5. Thuéry, P.; Harrowfield, J. Recent Advances in Structural Studies of Heterometallic UranylContaining Coordination Polymers and Polynuclear Closed Species. Dalton Trans. 2017, 46, $13660-13667$.

6. Wang, Y.; Liu, Z.; Li, Y.; Bai, Z.; Liu, W.; Wang, Y.; Xu, X.; Xiao, C.; Sheng, D.; Diwu, J.; Su, J.; Chai, Z.; Albrecht-Schmitt, T. E.; Wang, S. Umbellate Distortions of the Uranyl Coordination Environment Result in a Stable and Porous Polycatenated Framework that can Effectively Remove Cesium from Aqueous Solutions. J. Am. Chem. Soc. 2015, 137, 61446147.

7. Li, P.; Vermeulen, N. A.; Gong, X.; Malliakas, C. D.; Stoddart, J. F.; Hupp, J. T.; Farha, O. K. Design and Synthesis of a Water-Stable Anionic Uranium-Based Metal-Organic Framework (MOF) with Ultra Large Pores. Angew. Chem. Int. Ed. 2016, 55, 10358-10362. 
8. Li, P.; Vermeulen, N. A.; Malliakas, C. D.; Gómez-Gualdrón, D. A.; Howarth, A. J.; Mehdi, B. L.; Dohnalkova, A.; Browning, N. D.; O’Keeffe, M.; Farha, O. K. Bottom-up Construction of a Superstructure in a Porous Uranium-Organic Crystal. Science 2017, 356, 624-627.

9. Thuéry, P.; Atoini, Y.; Harrowfield, J. Tubelike Uranyl-Phenylenediacetate Assemblies from Screening of Ligand Isomers and Structure-Directing Counterions. Inorg. Chem. 2019, 58, $6550-6564$.

10. Thuéry, P.; Atoini, Y.; Harrowfield, J. 1,2-, 1,3-, and 1,4-Phenylenediacetate Complexes of the Uranyl Ion with Additional Metal Cations and/or Ancillary N-Donor Ligands: Confronting Ligand Geometrical Proclivities. Cryst. Growth Des. 2019, 19, 6611-6626.

11. Hooft, R. W. W. COLLECT, Nonius BV: Delft, The Netherlands, 1998.

12. Otwinowski, Z.; Minor, W. Processing of X-Ray Diffraction Data Collected in Oscillation Mode. Methods Enzymol. 1997, 276, 307-326.

13. Sheldrick, G. M. SHELXT - Integrated Space-Group and Crystal-Structure Determination. Acta Crystallogr., Sect. A 2015, 71, 3-8.

14. Sheldrick, G. M. Crystal Structure Refinement with SHELXL. Acta Crystallogr., Sect. C 2015, $71,3-8$.

15. Spek, A. L. Structure Validation in Chemical Crystallography. Acta Crystallogr., Sect. D 2009, $65,148-155$.

16. Farrugia, L. J. WinGX and ORTEP for Windows: an Update. J. Appl. Crystallogr. 2012, 45, 849-854.

17. Momma, K.; Izumi, F. VESTA 3 for Three-Dimensional Visualization of Crystal, Volumetric and Morphology Data. J. Appl. Crystallogr. 2011, 44, 1272-1276.

18. Blatov V. A.; Shevchenko, A. P.; Proserpio, D. M. Applied Topological Analysis of Crystal Structures with the Program Package ToposPro. Cryst. Growth Des. 2014, 14, 3576-3586. 
19. Thuéry, P.; Harrowfield, J. Uranyl-Organic Frameworks with Polycarboxylates: Unusual Effects of a Coordinating Solvent. Cryst. Growth Des. 2014, 14, 1314-1323.

20. Thuéry, P.; Harrowfield, J. Structural Variations in the Uranyl/4,4'-Biphenyldicarboxylate System. Rare Examples of 2D $\rightarrow$ 3D Polycatenated Uranyl-Organic Networks. Inorg. Chem. 2015, 54, 8093-8102.

21. Suzuki, T.; Kawasaki, T.; Ikeda, Y. Bis(1,3-dimethyl-1,3-diazinan-2-one)dinitratodioxidouranium(VI). Acta Crystallogr., Sect. E 2011, 67, m18.

22. Weis, E. M.; Duval, P. B.; Jurisson, S. S. Syntheses and structures of two uranyl complexes with DMPU. Radiochim. Acta 2012, 100, 237-241.

23. Thuéry, P.; Atoini, Y.; Harrowfield, J. 1,3-Adamantanedicarboxylate and 1,3Adamantanediacetate as Uranyl Ion Linkers: Effect of Counterions, Solvents and Differences in Flexibility. Eur. J. Inorg. Chem. 2019, 4440-4449.

24. Spackman, M. A.; Jayatilaka, D. Hirshfeld Surface Analysis. CrystEngComm 2009, 11, 1932.

25. Wolff, S. K.; Grimwood, D. J.; McKinnon, J. J.; Turner, M. J.; Jayatilaka, D.; Spackman, M. A. CrystalExplorer; University of Western Australia: Crawley, Australia, 2012.

26. Taylor, R.; Kennard, O. Crystallographic Evidence for the Existence of C-H $\cdots \mathrm{O}, \mathrm{C}-\mathrm{H} \cdots \mathrm{N}$, and C-H‥Cl Hydrogen Bonds. J. Am. Chem. Soc. 1982, 104, 5063-5070.

27. Desiraju, G. R. The C-H‥O Hydrogen Bond: Structural Implications and Supramolecular Design. Acc. Chem. Res. 1996, 29, 441-449.

28. Ikeda, Y.; Wada, E.; Harada, M.; Chikazawa, T.; Kikuchi, T.; Mineo, H.; Morita, Y.; Nogami, M.; Suzuki, K. A Study on Pyrrolidone Derivatives as Selective Precipitant for Uranyl Ion in $\mathrm{HNO}_{3}$. J. Alloys Compds. 2004, 374, 420-425. 
29. Thuéry, P.; Harrowfield, J. Complexes of Uranyl Ions with Aromatic Di- and Tetracarboxylates Involving $\left[\mathrm{Ni}(\text { bipy })_{n}\right]^{2+}(n=2,3)$ Counterions. Eur. J. Inorg. Chem. 2017, $5451-5460$.

30. Dance, I.; Scudder, M. Supramolecular Motifs: Concerted Multiple Phenyl Embraces between $\mathrm{Ph}_{4} \mathrm{P}^{+}$Cations are Attractive and Ubiquitous. Chem. Eur. J. 1996, 2, 481-486.

31. Thuéry, P.; Harrowfield, J. Uranyl Ion Complexes with 1,1'-Biphenyl-2,2',6,6'-tetracarboxylic Acid: Structural and Spectroscopic Studies of One- to Three-Dimensional Assemblies Inorg. Chem. 2015, 54, 6296-6305.

32. Liu, S. Origin and Nature of Bond Rotation Barriers: A Unified View. J. Phys. Chem. A 2013, $117,962-965$.

33. Gilli, P.; Pretto, L.; Bertolasi, V.; Gilli, G. Predicting Hydrogen-Bond Strengths from AcidBase Molecular Properties. The $\mathrm{p} K_{\mathrm{a}}$ Slide Rule: Toward the Solution of a Long-Lasting Problem. Acc. Chem. Res. 2009, 42, 33-44.

34. Schneider, H. J. Quantification of Noncovalent Interactions - Promises and Problems. New. J. Chem. 2019, 43, 15498-15512.

35. Harrowfield, J. M.; Richmond, W. R.; Sobolev, A. N.; White, A. H. Alkylammonium Cation Interactions with Calixarene Anions. Part 2. Structural Characterisation of a Salt of $2: 3$ Cation : Calixarene Stoichiometry. J. Chem. Soc., Perkin Trans 2 1994, 5-9.

36. Brachmann, A.; Geipel, G.; Bernhard, G.; Nitsche, H. Study of Uranyl(VI) Malonate Complexation by Time Resolved Laser-Induced Fluorescence Spectroscopy (TRLFS). Radiochim. Acta 2002, 90, 147-153.

37. Thuéry, P.; Harrowfield, J. Structural Consequences of 1,4-Cyclohexanedicarboxylate Cis/Trans Isomerism in Uranyl Ion Complexes: From Molecular Species to 2D and 3D Entangled Nets. Inorg. Chem. 2017, 56, 13464-13481. 
38. Xie, J.; Wang, Y.; Liu, W.; Lin, X.; Chen, L.; Zou, Y.; Diwu, J.; Chai, Z.; Albrecht-Schmitt, T. E.; Liu, G.; Wang, S. Highly Sensitive Detection of Ionizing Radiations by a Photoluminescent Uranyl Organic Framework. Angew. Chem. Int. Ed. 2017, 56, 7500-7504.

39. Wang, Y.; Yin, X.; Liu, W.; Xie, J.; Chen, J.; Silver, M. A.; Sheng, D.; Chen, L.; Diwu, J.; Liu, N.; Chai, Z.; Albrecht-Schmitt, T. E.; Wang, S. Emergence of Uranium as a Distinct Metal Center for Building Intrinsic X-ray Scintillators. Angew. Chem. Int. Ed. 2018, 57, 7883-7887. 
For Table of Contents Use Only

Structure-directing effects of coordinating solvents, ammonium and phosphonium counterions in uranyl ion complexes with

\section{1,2-, 1,3- and 1,4-phenylenediacetates}

Pierre Thuéry, Youssef Atoini and Jack Harrowfield

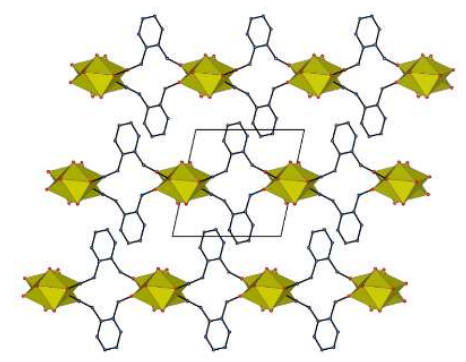

Depending on ligand conformation and structure-directing effects exerted by coligands or organic counterions, different mono- and diperiodic assemblies are formed by uranyl ions with the three isomers of phenylenediacetic acid. 